\title{
Neuroprotection of Catalpol for Experimental Acute Focal Ischemic Stroke: Preclinical Evidence and Possible Mechanisms of Antioxidation, Anti-Inflammation, and Antiapoptosis
}

\author{
Xia-wei Zheng, ${ }^{1}$ Wen-ting Yang, ${ }^{1}$ Shuang Chen, ${ }^{1}$ Qing-qing Xu, ${ }^{1}$ Chun-shuo Shan, ${ }^{1}$ \\ Guo-qing Zheng, ${ }^{1}$ and Ji-chen Ruan ${ }^{2}$ \\ ${ }^{1}$ Department of Neurology, The Second Affiliated Hospital and Yuying Children's Hospital of Wenzhou Medical University, \\ Wenzhou 32500, China \\ ${ }^{2}$ Department of Pediatric Hematology, The Second Affiliated Hospital and Yuying Children's Hospital of Wenzhou Medical \\ University, Wenzhou 325000, China
}

Correspondence should be addressed to Guo-qing Zheng; gq_zheng@sohu.com and Ji-chen Ruan; ruanjichen@163.com

Received 27 February 2017; Revised 4 May 2017; Accepted 14 May 2017; Published 13 July 2017

Academic Editor: Kumar Vaibhav

Copyright ( 92017 Xia-wei Zheng et al. This is an open access article distributed under the Creative Commons Attribution License, which permits unrestricted use, distribution, and reproduction in any medium, provided the original work is properly cited.

\begin{abstract}
Neuroprotection is defined as using a therapy that affects the brain tissue in the still-viable ischemic penumbra to salvage or delay the infarction. Catalpol, the main active principle of the root of Radix Rehmanniae, was reported to have pleiotropic neuroprotective effects in neurodegenerative diseases including ischemic stroke. Here, we evaluated the neuroprotective effects of catalpol in experimental acute ischemic stroke. Studies on catalpol in animal models of acute ischemic stroke were identified from 6 databases. Twenty-five studies involving 805 animals were included. Twelve comparisons showed significant effects of catalpol on decreasing infarct size according to 2,3,5-triphenyltetrazolium chloride staining compared with the control $(P<0.05)$. One study reported significant effect of catalpol on reducing infarct size according to magnetic resonance imaging scan compared with the control $(P<0.05)$. Meta-analysis of these studies indicated that catalpol significantly improved the neurological function score according to Zea Longa score, Bederson score, balance beam-walking test, adhesive removal test, bar-grasping score, and corner test compared with the control $(P<0.05)$. In conclusion, catalpol exerted neuroprotective effects for experimental acute focal ischemic stroke, largely through reducing oxidative reactions, inhibiting apoptosis, and repressing inflammatory reactions and autophagy. However, these apparently positive findings should be interpreted with caution because of the methodological flaws.
\end{abstract}

\section{Introduction}

Neuroprotection refers to the concept of using a therapy that affects the brain tissue in the still-viable ischemic penumbra to salvage or delay the infarction $[1,2]$. Possible mechanisms of neuroprotective treatments are to prevent local inflammation, excitotoxicity, free radical damage, neuronal apoptosis, and calcium influx into cells, resulting in both improvement of functional outcomes and reduction of infarct size [3]. In the past decades, a wealth of research has been conducted into the development of numerous neuroprotective treatments capable of reducing brain damage following ischemic stroke of animal models [4]. However, up to now, clinical trials have not identified efficacious neuroprotective therapies for stroke patients [5]. Thus, given the huge translational gap between these animal studies and clinical trials, seeking or developing innovative neuroprotectants is urgently needed. Radix Rehmanniae (Latin name), rehmannia root (English name), Dihuang (Chinese name), the roots of Radix Rehmanniae Recens, was first recorded in the book of Shennongbencaojing (Shennong's Classic of Materia Medica) - the earliest complete pharmacopoeia of China. In modern times, Radix Rehmanniae and Radix Rehmanniae-based prescriptions are still widely used for treatment of various diseases in China and elsewhere worldwide [6, 7]. Radix Rehmanniae exerts its pharmacological actions on the endocrine system, 
blood system, immune system, nervous system, cardiovascular system, and so forth [8]. Catalpol (Figure 1), an iridoid glucoside, is the main active principle of the root of Radix Rehmanniae. Recent studies reported that catalpol had pleiotropic neuroprotective effects against hypoxic/ischemic injury, Alzheimer's disease, and Parkinson's disease in both in vivo and in vitro models [9]. Catalpol had been found to have antioxidation, anti-inflammation, antiapoptosis, and other neuroprotective properties [9], suggesting the potential neuroprotective effect of catalpol on stroke [10].

Systematic reviews are considered as the highest level of medical evidence; only data from systematic reviews will be proposed as la-evidence according to the levels of evidence from the Centre of Evidence-Based Medicine in Oxford [11]. Preclinical systematic reviews are a novel approach to appraise and synthesize results from animal research into a single and useful document that can indicate the direction for further basic research, reduce and refine the experimental studies, and enhance the rate of success in future clinical trials [12]. However, no systematic analysis has yet been conducted to assess the efficacy of catalpol for experimental ischemic stroke. Therefore, we aimed to identify the current evidence of catalpol as neuroprotective agent in animal models of acute focal ischemic stroke.

\section{Methods}

2.1. Search Strategy. Experimental studies of catalpol for acute focal ischemic stroke were identified from PubMed, Web of Science, Excerpta Medica Database (EMBASE), Wanfang Data information site, Chinese National Knowledge Infrastructure (CNKI), and VIP information database. All searches were performed from inception to April 2017. Chinese databases were searched by using the following search terms: "Catalpol" AND ["ischemic stroke" OR "cerebral infarct" OR "middle carotid artery occlusion (MCAO)" OR "cerebral ischemia/reperfusion"]. The term used in English databases was merely "Catalpol." We manually searched dissertations, conference proceedings, and reference lists of identified publications relevant to this topic.

2.2. Eligibility. Experimental studies on catalpol for acute permanent MCAO or temporary MCAO models and compared with vehicle or no treatment were included. Meanwhile, the primary outcome measurements should be neurological function score (NFS) and/or infarct volume (IV). Exclusion criteria were prespecified as follows: (1) the article was a review, case report, comment, only an abstract, or editorial; (2) the article was not an animal study; (3) the article was not a research about acute focal cerebral ischemia model, such as traumatic, global, chronic cerebral ischemic models or not cerebral ischemic models; (4) catalpol was not used as a monothrapy; (5) neither NFS nor IV was used as one of the outcome measurements; (6) there was not a control group in the study; (7) the article was a duplicate publication.

2.3. Quality Assessment. The methodological quality of each included study was evaluated by using Collaborative

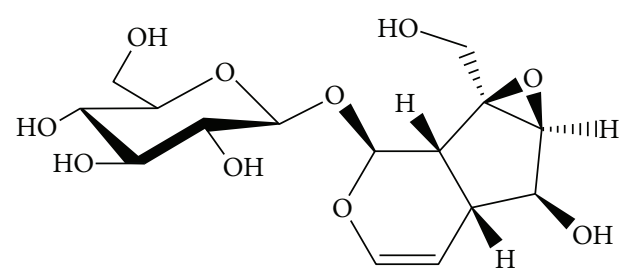

Figure 1: Chemical structure of catalpol.

Approach to Meta-Analysis and Review of Animal Data from Experimental Studies (CAMARADES) 10-item checklist [13]: (1) peer-reviewed publication; (2) statements describing control of temperature; (3) randomization to treatment group; (4) allocation concealment; (5) blinded assessment of outcome; (6) avoidance of anesthetics with known notable intrinsic neuroprotective properties; (7) use of animals with relevant comorbidities; (8) sample size calculation; (9) compliance with animal welfare regulations; (10) declared any potential conflict of interest. For calculating an aggregate quality score, each item of this scale was attributed one point. Two authors (ZXW and YWT) independently extracted information and evaluated quality study. Disagreements were solved after discussing the details of the studies.

2.4. Data Extraction. The following information of each included study was extracted: (1) the first author's name and publication year, permanent or temporary MCAO, ischemic time, the anesthetic used, and random method; (2) characteristics of animals, including sex, species, weight, and animal number; (3) treatment information, including the drug used, method of treatment, timing for initial treatment, and duration of treatment; (4) outcome measurements, timing for outcome assessments, and corresponding data of mean value, standard deviation, and between-group differences. NFS and/or IV was extracted separately. If outcomes were presented at different time points, we extracted data from the last time point. If studies utilized dose gradient of the drug, we extracted data from the highest dose of catalpol because of the prespecific criteria and the dose-response relationship. If the data were incomplete or presented in graphs, we tried to contact the authors for data needed or calculated using relevant software.

Information of the mechanism studies of catalpol for experimental ischemic stroke among the included articles and other compounds from Rehmanniae Radix was extracted as the following: the first author name, publication year, models used in experiment, interventions in experimental group and control group, observation, and possible mechanisms.

2.5. Statistical Analysis. All data of NFS and IV were considered as continuous variables. Meta-analysis was performed with RevMan version 5.0. The random effect model and standard mean difference (SMD) were utilized herein. The $I^{2}$ statistics were chosen for the assessment of heterogeneity. Furthermore, to explore potential sources of high heterogeneity, subgroup analyses were performed according to timing for outcome assessments and sex of animals. Difference 


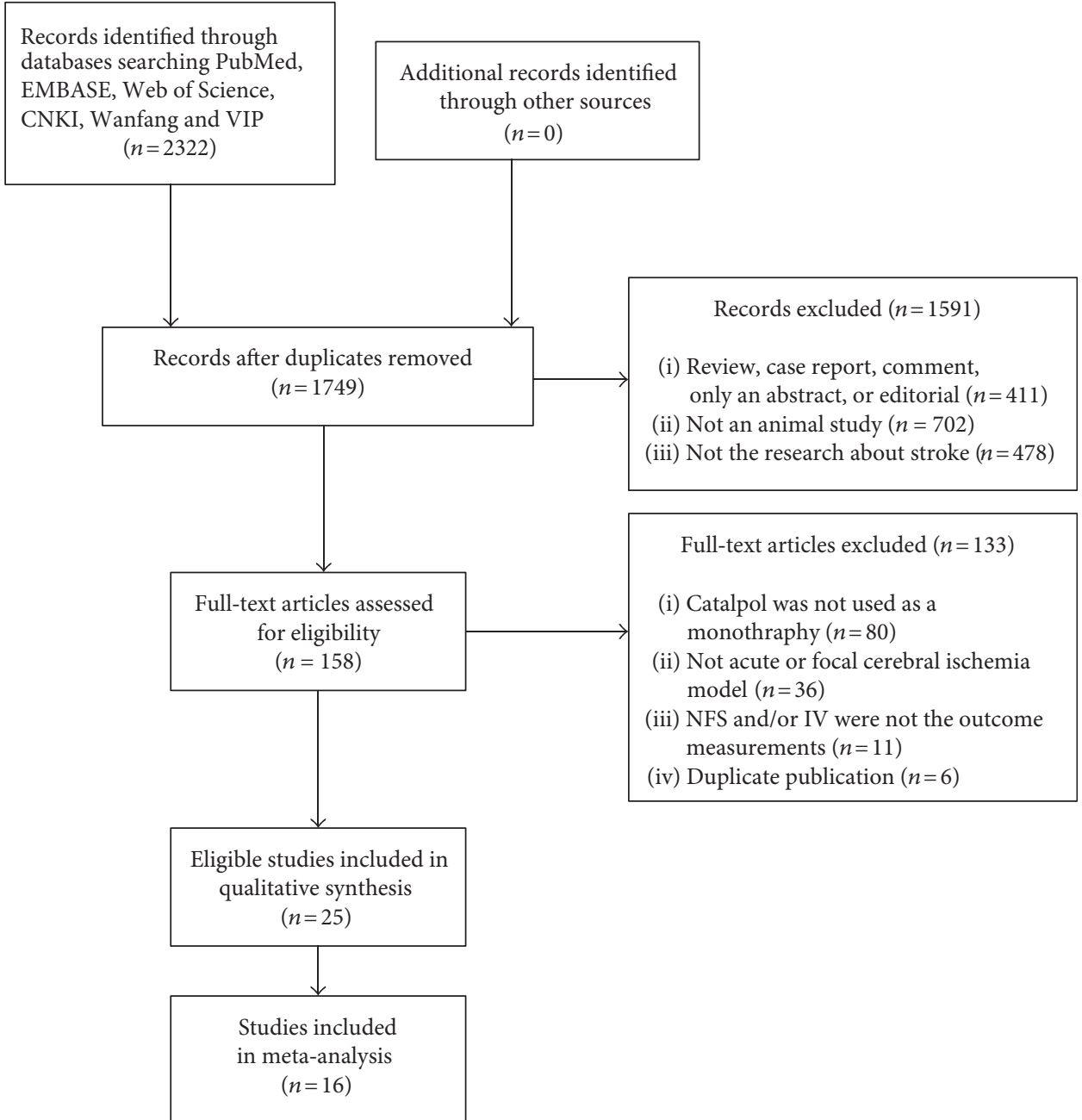

Figure 2: Flow diagram.

between groups was determined by partitioning heterogeneity and utilizing the $\chi^{2}$ distribution with degrees of freedom (df). When probability value was less than 0.05 , the difference was considered significant.

\section{Results}

3.1. Study Inclusion. We identified 2322 papers after systematical searches of six databases. After removing duplicates, 1749 records remained. By reading the titles and abstracts, 1591 articles were excluded for at least one of the following reasons: (1) the article was a review, case report, comment, only an abstract, or editorial; (2) the article was not an animal study; (3) the article was not a research about cerebral ischemia or stroke. After reviewing the full text of the remaining 158 papers, 80 studies were excluded because catalpol was not used as a monothrapy; 36 studies were excluded because the animal model was not acute focal cerebral ischemia; 11 studies were removed because the outcome measurement was neither NFS nor IV; 6 studies were excluded because they are duplicate publications. Ultimately, 25 eligible articles were identified [14-38] (Figure 2).
3.2. Methodological Quality of Included Studies. The quality scores of the 25 included studies ranged from 2 to 7 points. One study [23] got 2 points; 8 studies [16, 19, 20, 24, 28, $30,34,35]$ got 3 points; 11 studies [18, 21, 22, 25-27, 29, $32,33,36,37]$ got 4 points; one study [15] got 5 points; 3 studies [17, 31, 38] got 6 points; one study [14] got 7 points (Table 1). The average score was 4.00 . Eight studies were online Master's thesis or Ph.D. thesis and not formally published. Seven unpublished Master's theses were from Zhou 2008, Xue 2012, Wang 2013, Wang 2015, Min 2015, Qin 2016, and Zhang 2011 [18, 19, 22, 25, 32, 36, 37]. One unpublished Ph.D. thesis was from Liu 2011 [23]. Seven studies described control of temperature [14, 16, 25, 27, 29, 31, 33]. Random allocation to treatment group was described in 21 studies [15, 17-24, 26-34, 36-38], and 2 studies used the method of random digit table $[21,33]$. No study reported allocation concealment. Blinded assessment of outcome was described in 4 studies [14, 15, 17, 21, 22]. Twenty-one studies did not use anesthetics with significant intrinsic neuroprotective activity, and the remaining 4 studies did not report the type of anesthetics $[15,16,23,24]$. No study used animals with relevant comorbidities. One study described the sample size calculation [14]. Eleven studies 
TABLE 1: Quality assessment of included studies.

\begin{tabular}{|c|c|c|c|c|c|c|c|c|c|c|c|}
\hline Study (years) & 1 & 2 & 3 & 4 & 5 & 6 & 7 & 8 & 9 & 10 & Total \\
\hline Jia et al. [14] & + & + & - & - & + & + & - & + & + & + & 7 \\
\hline Wan et al. [15] & + & - & + & - & + & NR & - & - & + & + & 5 \\
\hline Wan et al. 2013 [16] & + & + & - & - & - & NR & - & - & + & - & 3 \\
\hline Zhu et al. [17] & + & - & + & - & + & + & - & - & + & + & 6 \\
\hline Wang [18] & - & - & + & - & - & + & - & - & + & + & 4 \\
\hline Xue [19] & - & - & + & - & - & + & - & - & - & + & 3 \\
\hline Zhang et al. [20] & + & - & + & - & - & + & - & - & - & - & 3 \\
\hline Min et al. [21] & + & - & + & - & + & + & - & - & - & - & 4 \\
\hline Min [22] & - & - & + & - & + & + & - & - & - & + & 4 \\
\hline Liu 2011 [23] & - & - & + & - & - & NR & - & - & - & + & 2 \\
\hline Wan et al. 2012 [24] & + & - & + & - & - & NR & - & - & - & + & 3 \\
\hline Wang [25] & - & + & - & - & - & + & - & - & + & + & 4 \\
\hline Wang et al. [26] & + & - & + & - & + & + & - & - & - & - & 4 \\
\hline Liu et al. 2011 [27] & + & + & + & - & - & + & - & - & - & - & 4 \\
\hline Liu et al. 2011 [28] & + & - & + & - & - & + & - & - & - & - & 3 \\
\hline Zhang et al. 2013 [29] & + & + & + & - & - & + & - & - & - & - & 4 \\
\hline Zhang et al. 2013 [30] & + & - & + & - & - & + & - & - & - & - & 3 \\
\hline Wan et al. 2012 [31] & + & + & + & - & - & + & - & - & + & + & 6 \\
\hline Zhou [32] & - & - & + & - & - & + & - & - & + & + & 4 \\
\hline Wan et al. 2013 [33] & + & + & + & - & - & + & - & - & - & - & 4 \\
\hline Tan et al. [34] & + & - & + & - & - & + & - & - & - & - & 3 \\
\hline Zhang et al. [35] & + & - & - & - & - & + & - & - & - & + & 3 \\
\hline Qin [36] & - & - & + & - & - & + & - & - & + & + & 4 \\
\hline Zhang [37] & - & - & + & - & - & + & - & - & + & + & 4 \\
\hline Wan et al. [38] & + & - & + & - & + & + & - & - & + & + & 6 \\
\hline
\end{tabular}

1: peer-reviewed publication; 2: statements describing control of temperature; 3: randomization to treatment group; 4: allocation concealment; 5: blinded assessment of outcome; 6: avoidance of anesthetics with known notable intrinsic neuroprotective properties; 7: use of animals with relevant comorbidities; 8: sample size calculation; 9: compliance with animal welfare regulations; 10: declared any potential conflict of interest; NR: not reported.

reported compliance with animal welfare regulations [14-18, $25,31,32,36-38]$. Fifteen studies mentioned statement of potential conflict of interests $[14,15,17-19,22-25,31$, 32, 35-38].

3.3. Study Characteristics. Twenty-five studies with 805 animals were included. Among them, 5 studies [14-17, 38] were published in English and 20 studies were Chinese papers between 2008 and 2016. Twenty-one studies used male and/or female Sprague Dawley (SD) rats; one study [14] used male Wistar rats; four studies [16, 18-20] used Kunming mice. The weight of SD rats used varied from $180 \mathrm{~g}$ to $350 \mathrm{~g}$; the weight of Wistar rats used varied from $250 \mathrm{~g}$ to $300 \mathrm{~g}$; the weight of mice varied from $22 \mathrm{~g}$ to $35 \mathrm{~g}$. Chloral hydrate was used to induce anesthesia in 18 studies, pentobarbital in 2 studies $[21,22]$, and isoflurane in 1 study [14]; while the remaining 4 studies did not report the type of anesthetics $[15,16,23,24]$. Nineteen out of the 25 studies utilized permanent MCAO models, and the remaining six studies $[14,21-23,25,26]$ were temporary MCAO models in which ischemic time varied from 1 to 2 hours. Fifteen studies utilized a dose gradient of catalpol: six studies [23, $27-30,35]$ administrated 15,30 , and $60 \mathrm{mg} \mathrm{kg}^{-1}$ intragastrically, four studies $[18,24,25,31]$ used 1,5 , and $10 \mathrm{mg} \mathrm{kg}^{-1}$ intraperitoneally, two studies $[21,22]$ used 1 and $5 \mathrm{mg} \mathrm{kg}^{-1}$ intraperitoneally, one study [32] used 1,3 , and $5 \mathrm{mg} \mathrm{kg}^{-1}$ intraperitoneally, one study [36] used 5 and $10 \mathrm{mg} \mathrm{kg}^{-1}$ intraperitoneally, and one study [18] used 1.42, 7, and $14.2 \mathrm{mg} \mathrm{kg}^{-1}$ intraperitoneally. Twenty-three studies administrated catalpol after stroke; one study administrated catalpol before stroke [14]; and two studies administrated catalpol before and after stroke $[18,25]$. In the control group, 14 studies applied same volume of normal saline; 3 studies [23, 28, 36] applied edible oil; one study [14] applied saline; one study [27] applied distilled water; one study [21] applied dimethyl sulfoxide; one study [37] applied 1,2-propylene glycol; 2 studies [29, 35] applied edible oil and normal saline; and 4 studies $[20,22,26,38]$ applied no treatment. Thirteen studies $[14,16,18-22,24,25,29,31$, 33 , 37] adopted IV as outcome measurements; twenty-five studies used NFS as outcome measurements; and 13 studies adopted both above two outcome measurements. However, the methods used to identify IV were different; 11 studies used TTC staining and 2 studies [24, 33] used MRI scan. The standards of NFS were diverse: 13 studies [14, 16, 19-23, 26-29, 35, 37] adopted Zea Longa (ZL) score; 11 studies $[15,17,18,23,27-29,31,32,34,37]$ used balance beam-walking test; 7 studies $[15,17,18,25,31,32,36]$ 


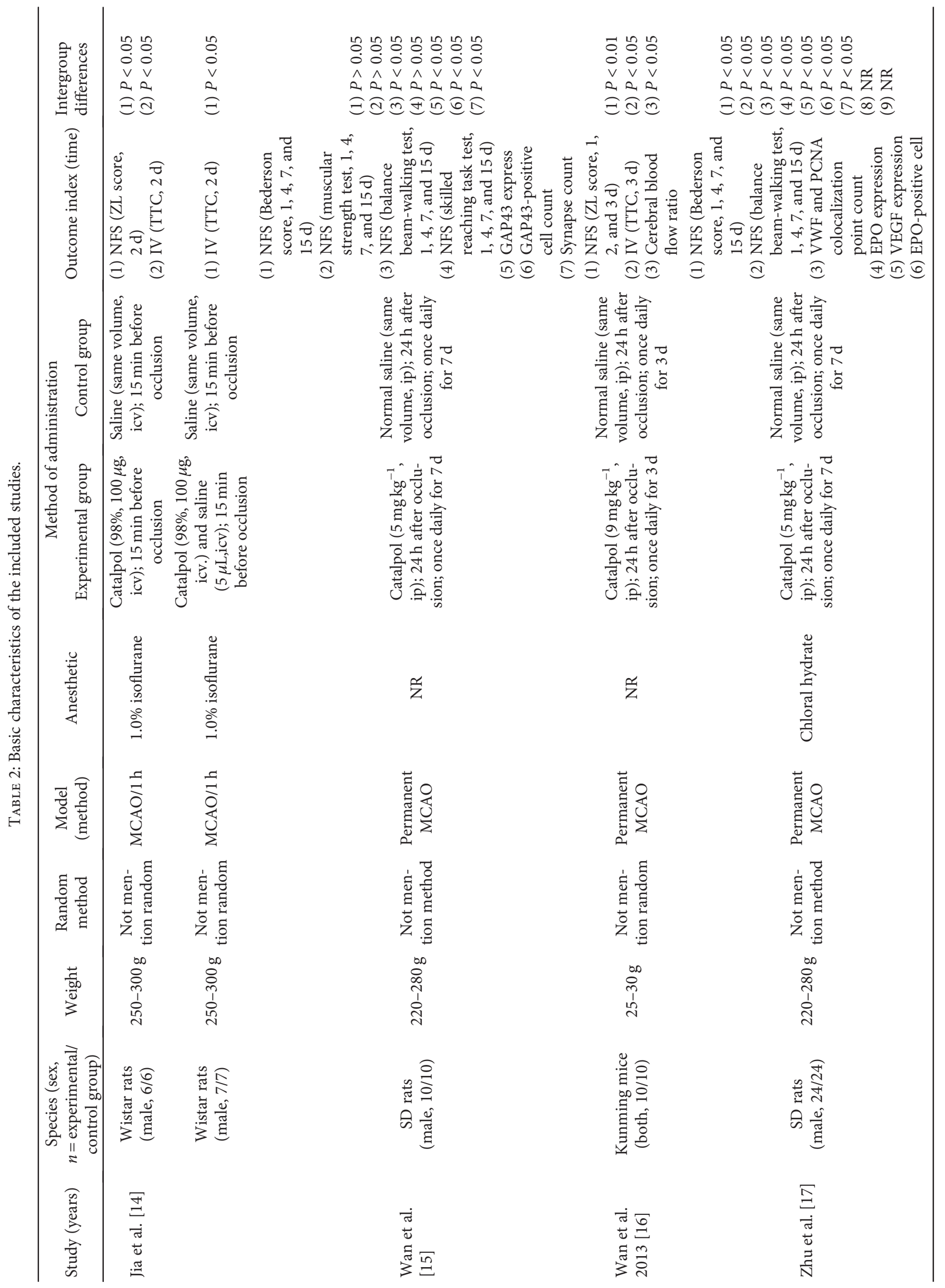




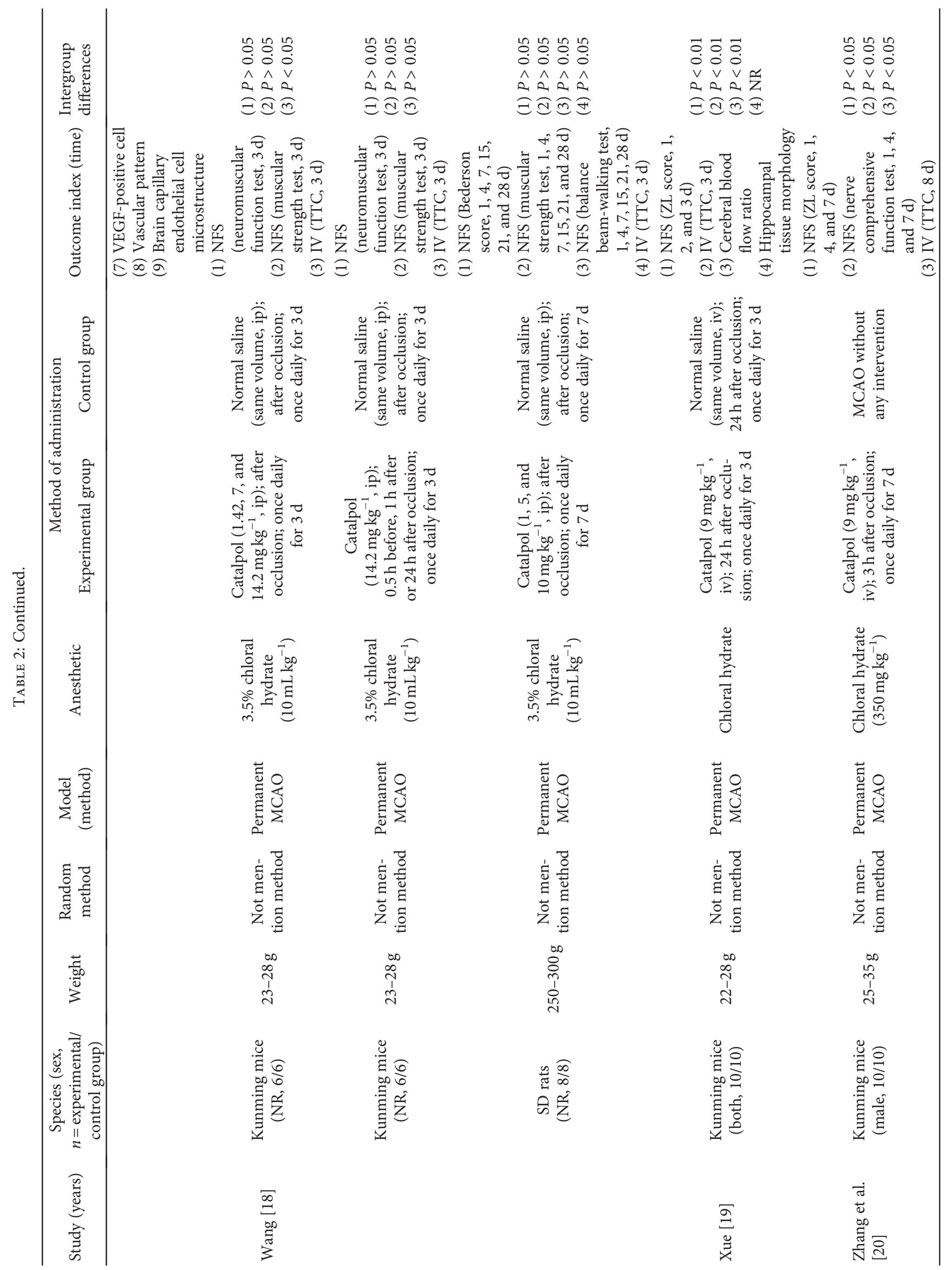




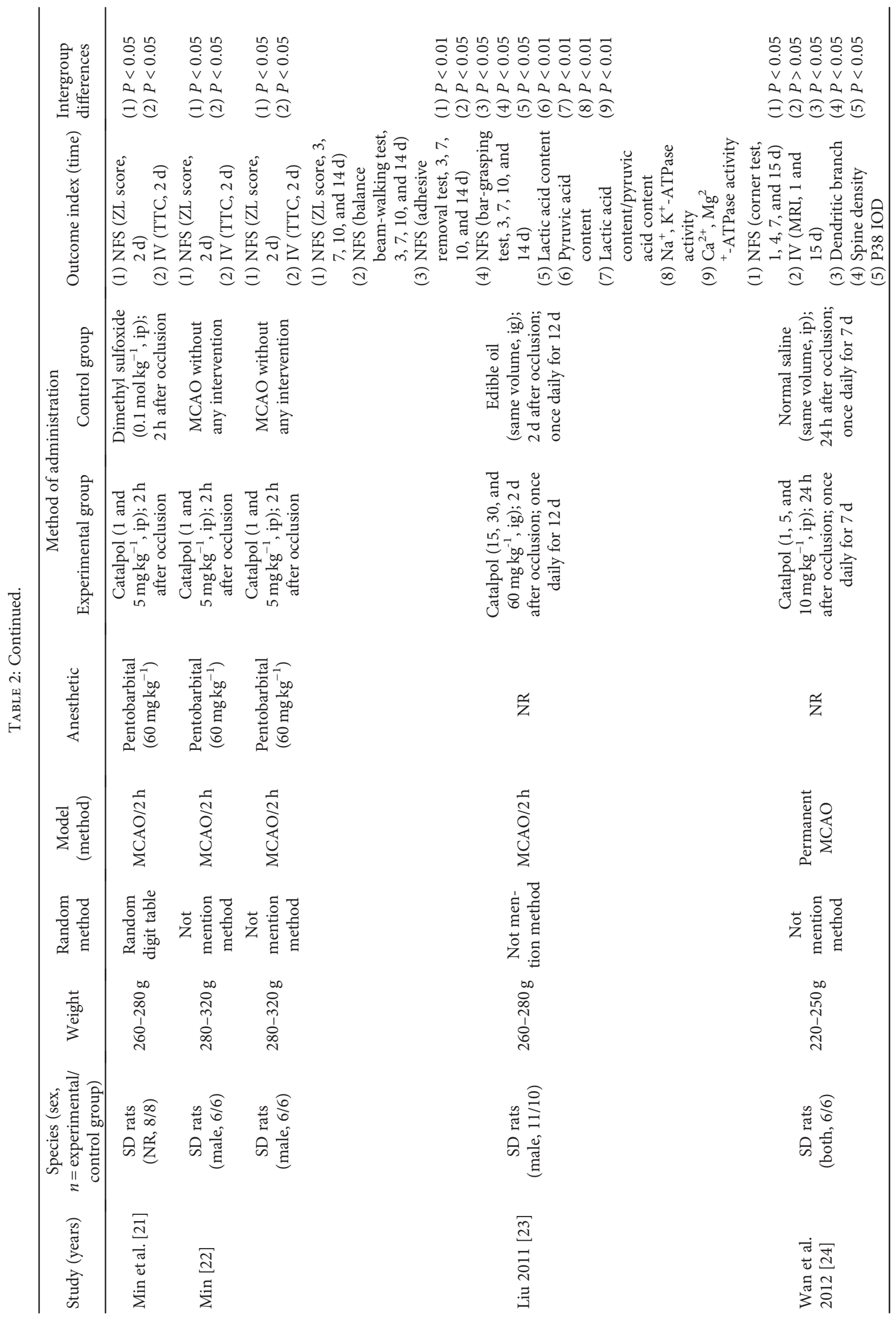




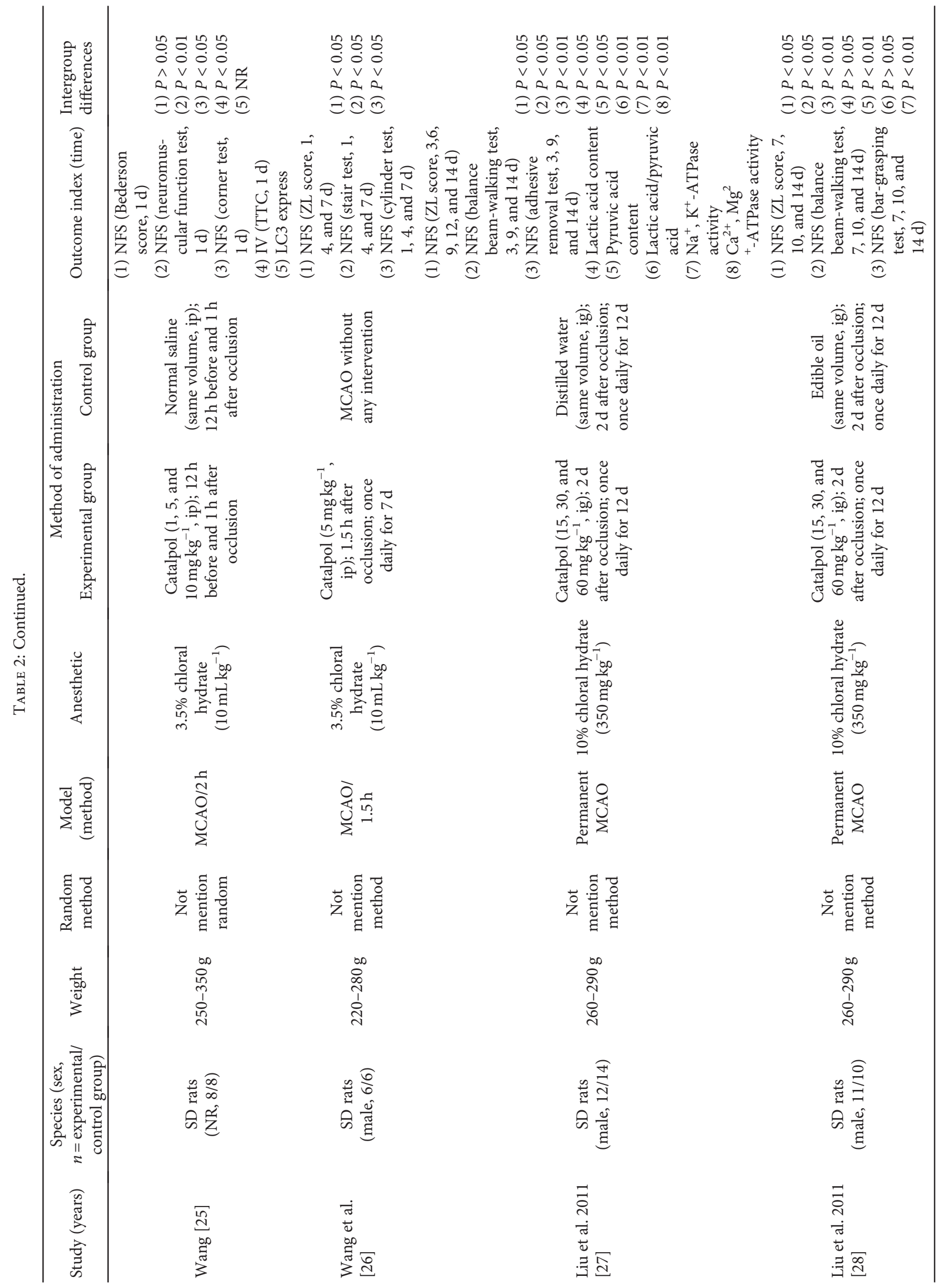




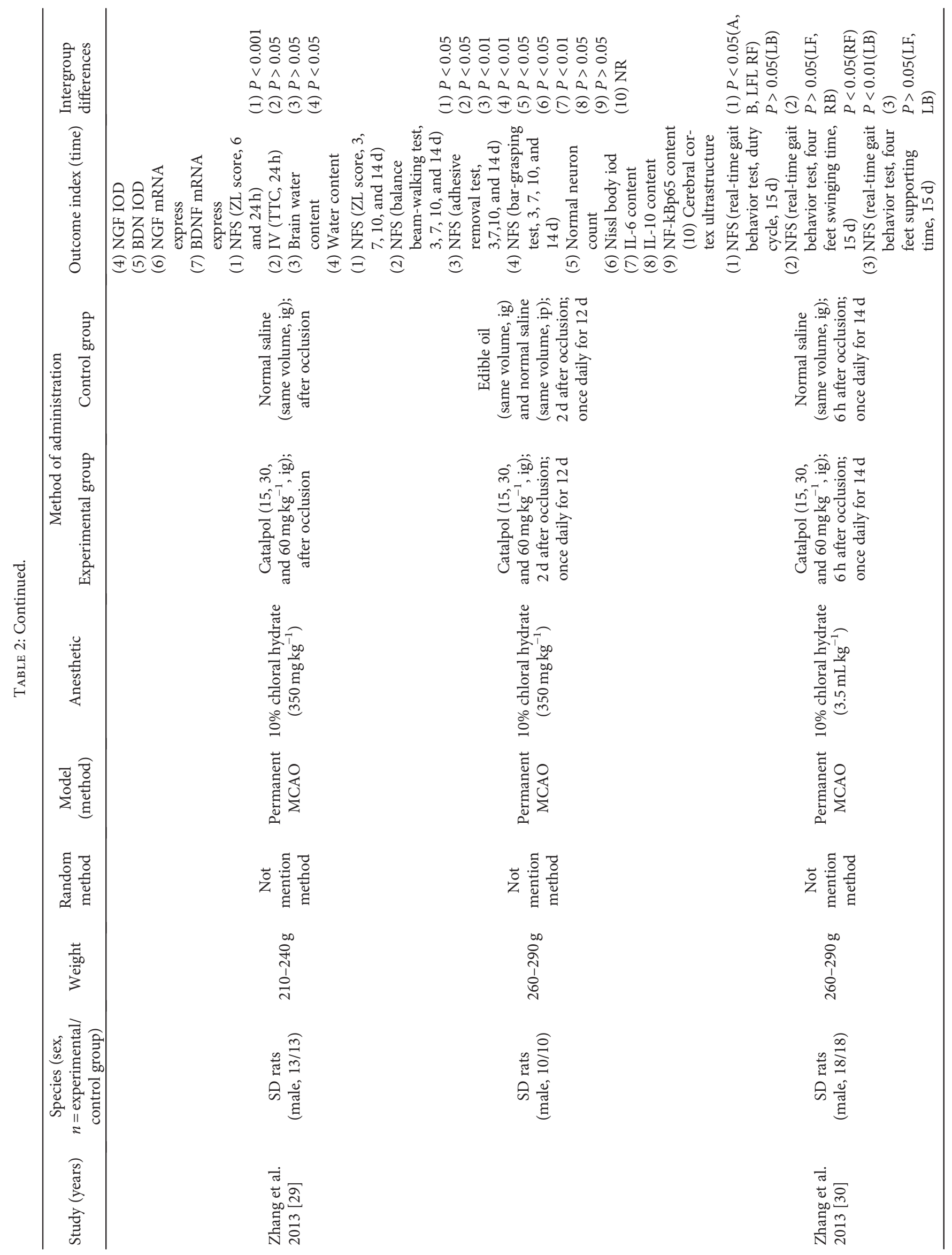




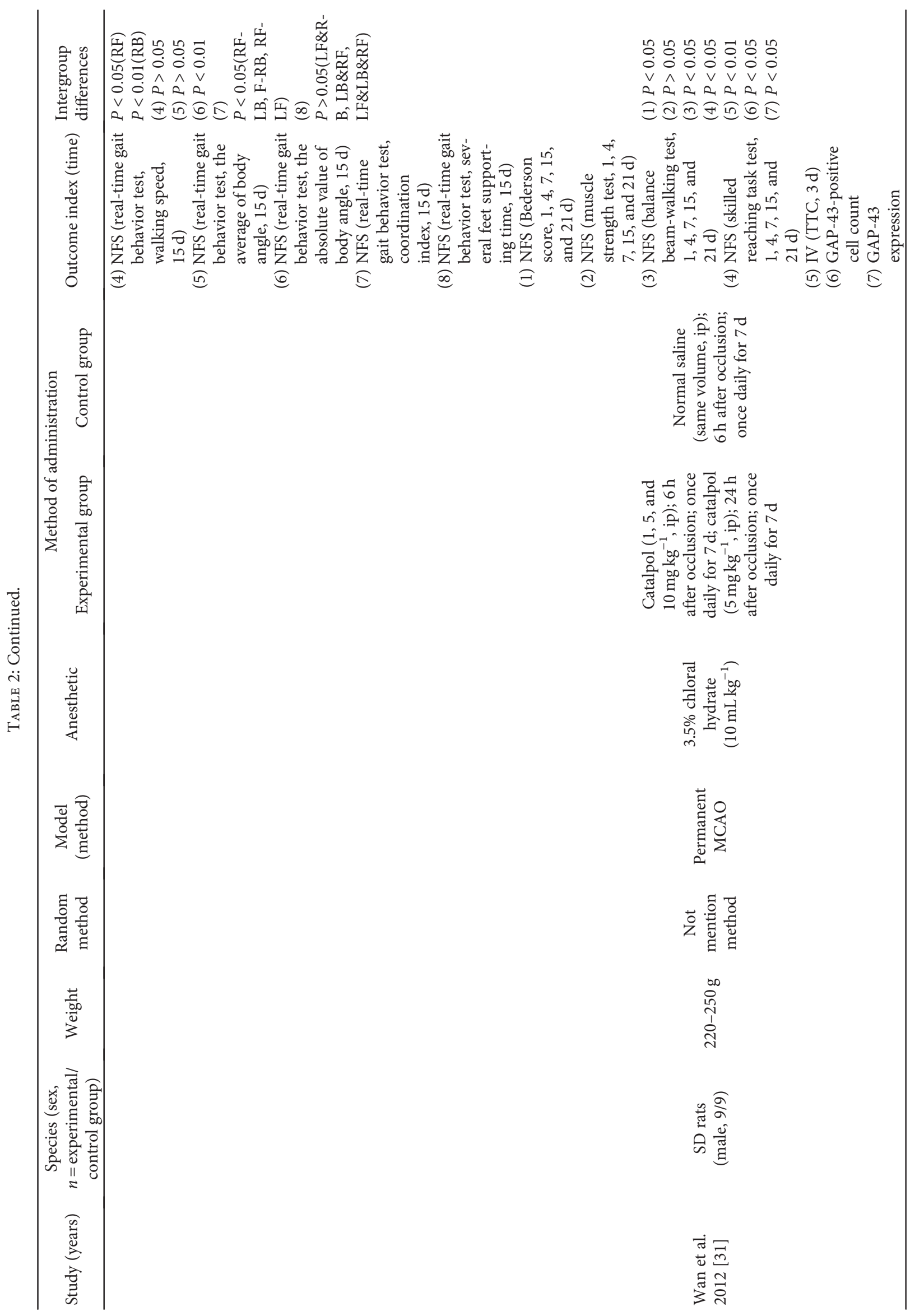




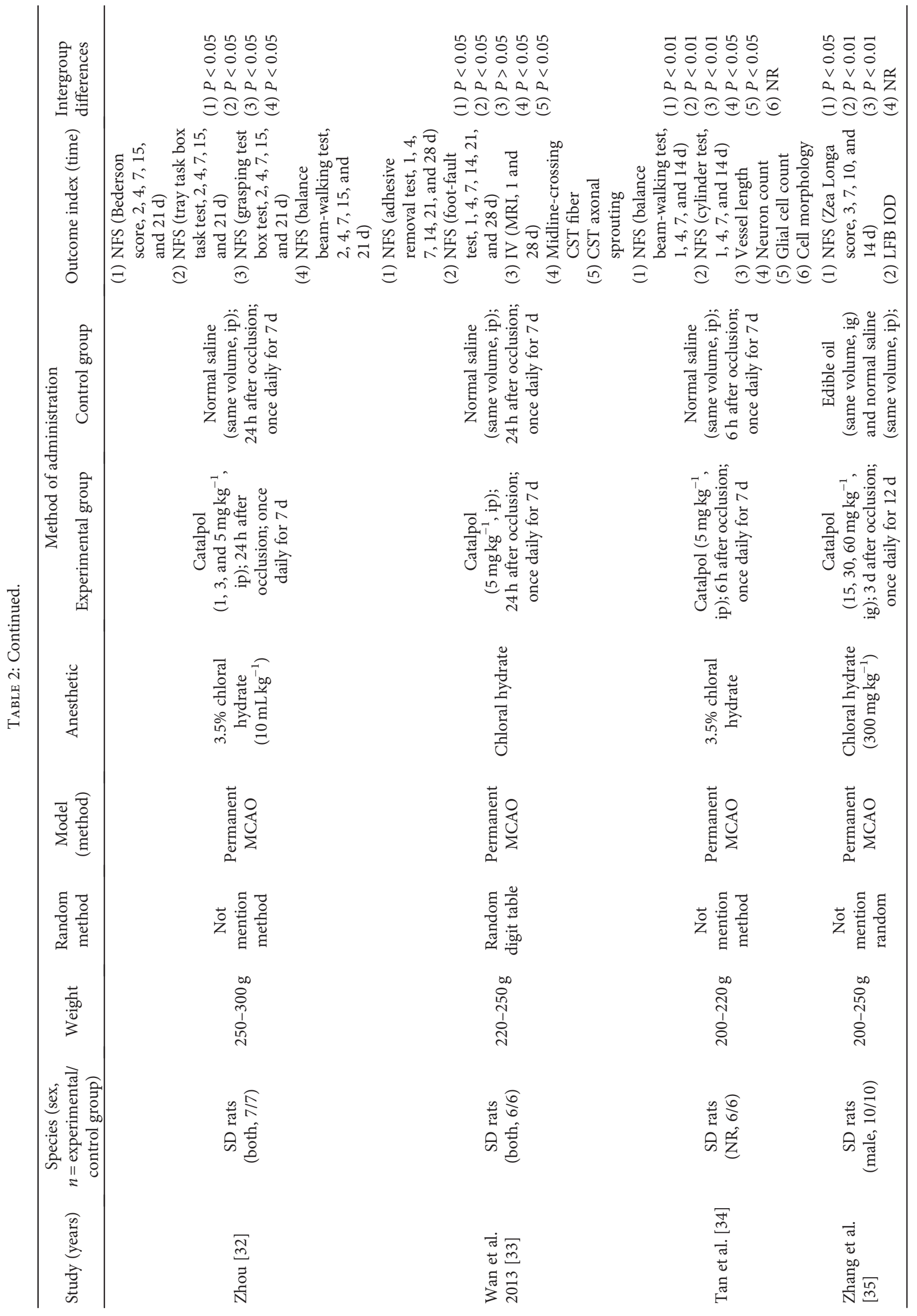




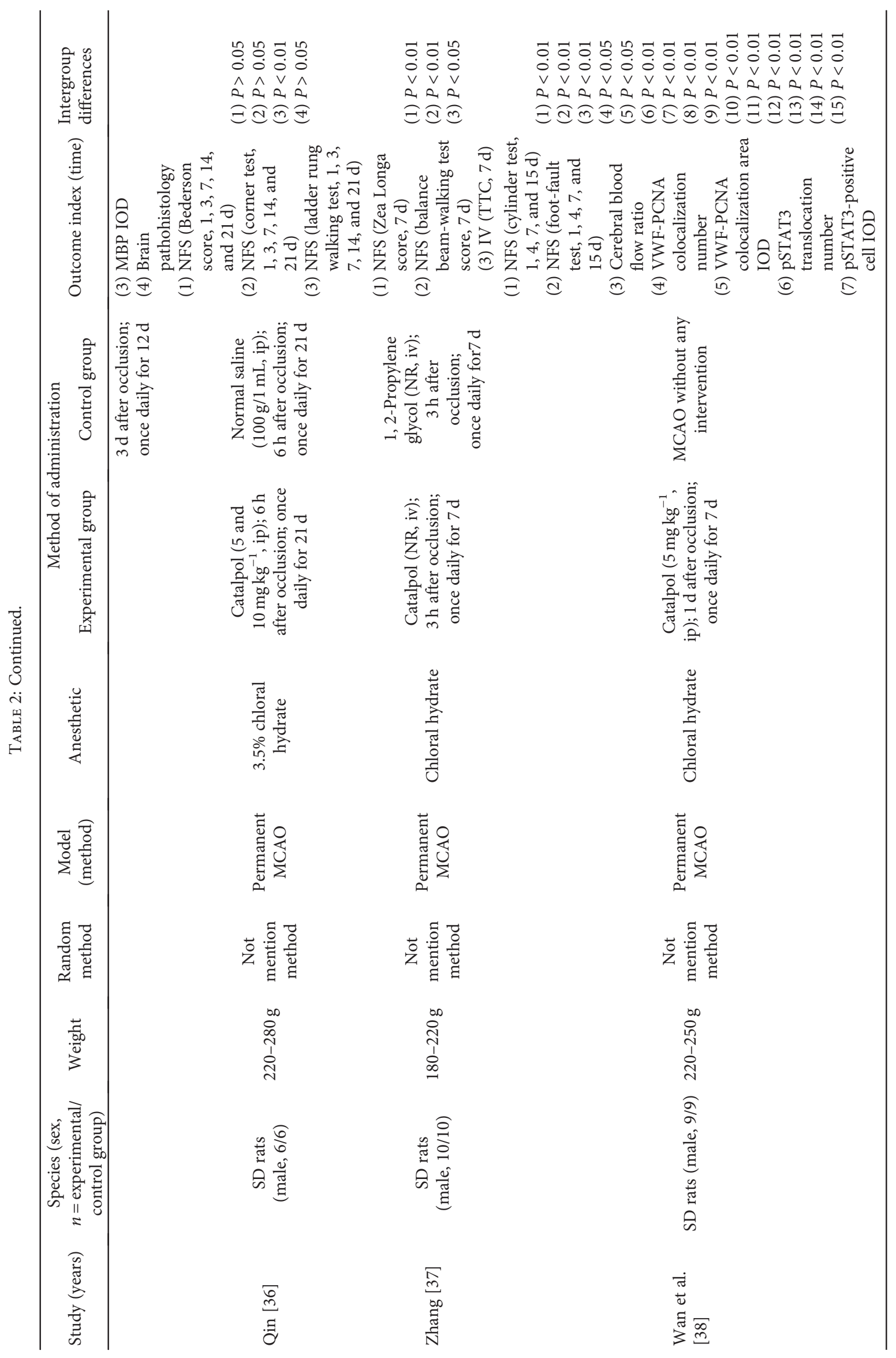




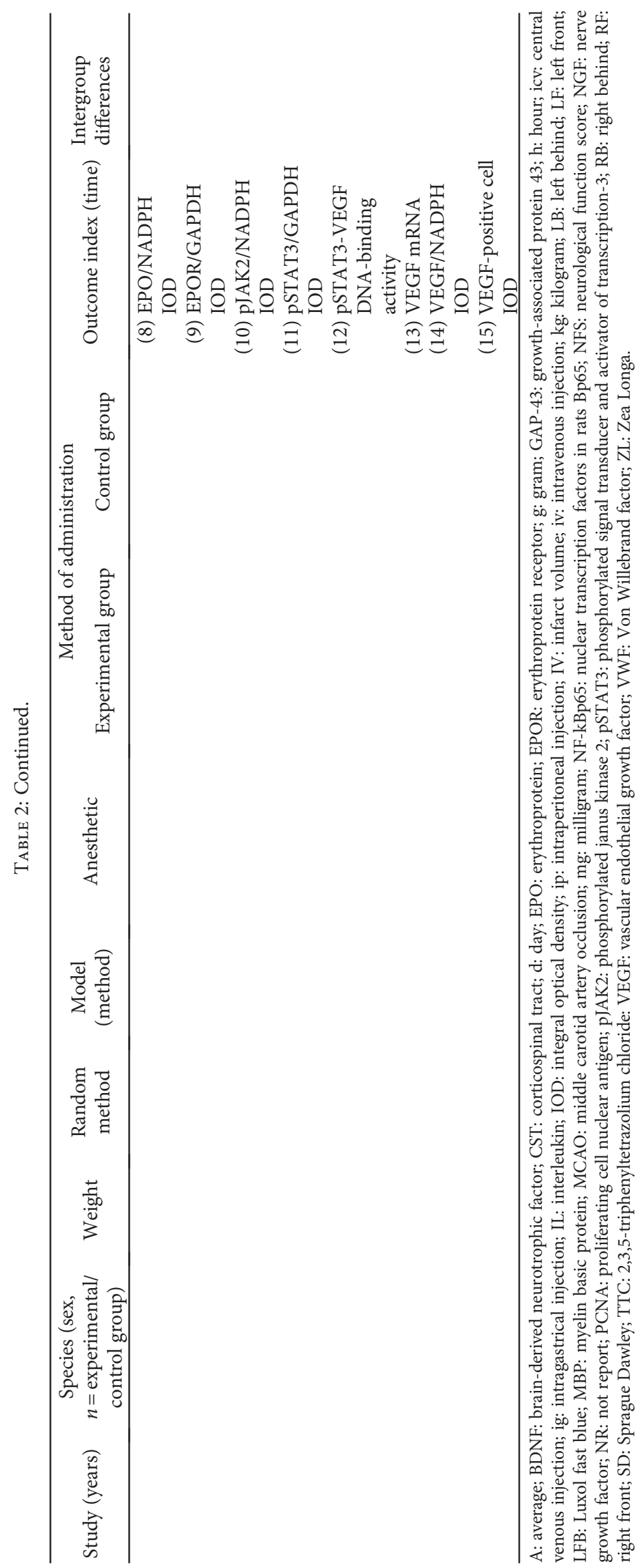




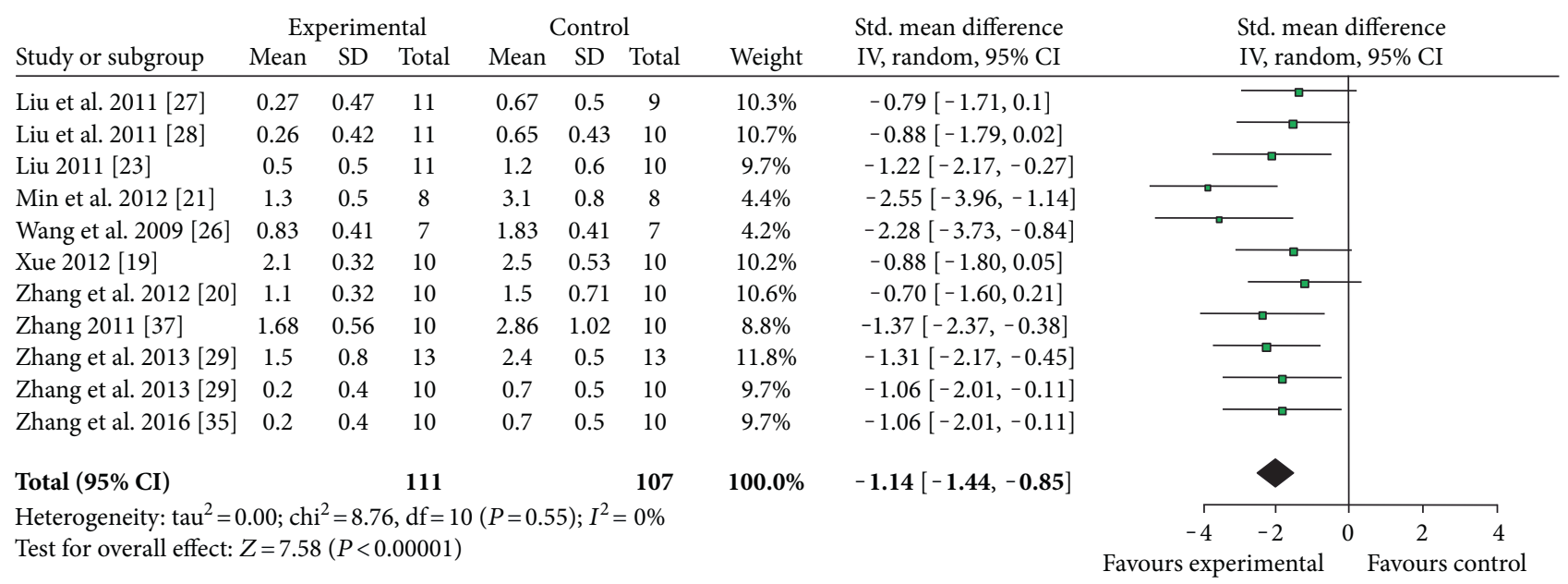

(a)

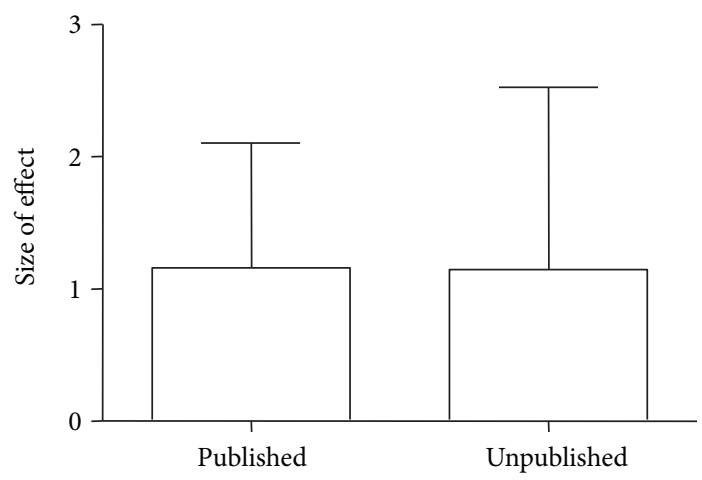

(b)

FIGURE 3: (a) The forest plot: effects of catalpol for improving NFS according to ZL score compared with the control; (b) subgroup analysis of Zea Longa score by published or not.

used Bederson score; 4 studies [23, 27, 29, 33] used adhesive removal test; 3 studies $[15,18,31]$ used muscular strength test; 3 studies [23, 28, 29] used bar-grasping test; 3 studies [24, 25, 36] used corner test; and 3 studies [26, $34,38]$ used cylinder test. From another perspective, neuromuscular function test $[18,25]$, skilled reaching task test $[15,31]$, and foot-fault test $[33,38]$ were utilized in 2 studies. Nerve comprehensive function test [20], stair test [26], tray task box task test [32], grasping test box test [32], real-time gait behavior test [30], and ladder rung walking test were utilized in 1 study. The basic characteristics of the 25 studies were shown in Table 2 .

3.4. Effectiveness. Eleven studies (15 comparisons) used IV based on TTC staining as outcome measurement. Fourteen comparisons of these studies $[14,16,18-22,25,29,31,38]$ reported that catalpol could significantly reduce IV compared with the control $(P<0.05)$; one comparison [18] showed no significant effect of catalpol for decreasing IV compared with the control, according to TTC staining. Two studies adopted IV based on MRI scan as outcome measurement. One study [33] reported significant effects of catalpol for reducing IV according to MRI scan compared with the control $(P<0.05)$, whereas the other one [24] reported no significance.
Various measuring methods of NFS were used as follows: (1) ZL score (13 studies with 15 comparisons): meta-analysis of 11 comparisons [19-21, 23, 26-29, 35, 37] indicated significant effect of catalpol for improving the NFS compared with the control. $(n=218, \mathrm{SMD}=-1.14,95 \% \mathrm{CI}:-1.44 \sim-0.85$, $P<0.00001$; heterogeneity $\chi^{2}=8.76, \mathrm{df}=10, \quad P=0.55$, $I^{2}=0 \%$, Figure $\left.3(\mathrm{a})\right)$. The remaining four comparisons [14, 16, 22] also showed significance $(P<0.05$ or $P<0.01)$ but failed to pool analysis due to the absence of primary data. Furthermore, there were three not formally published theses $[19,23,37]$ out of 10 studies, which may lead to an inaccurate assessment of the effects of the intervention [39]. Thus, we conducted subgroup analysis and the result showed that there was no difference in effect size between published studies and unpublished studies (Figure 3(b)). (2) Balance beam-walking test (11 studies): meta-analysis of 8 studies $[23,27-29,31,32,34,37]$ showed no significant effect of catalpol for improving the NFS compared with the control $(n=141, \quad \mathrm{SMD}=-1.01, \quad 95 \% \quad \mathrm{CI}:-2.33 \sim 0.31, \quad P=0.14$; heterogeneity $\left.\chi^{2}=68.21, \mathrm{df}=7, P<0.00001 ; I^{2}=90 \%\right)$. As the value of $I^{2}$ was greater than $50 \%$, subgroup analyses were conducted to explore potential sources of high heterogeneity according to timing for outcome assessments. Meta-analysis of two studies [31, 32] in the 21th day subgroup showed that catalpol significantly improved NFS 


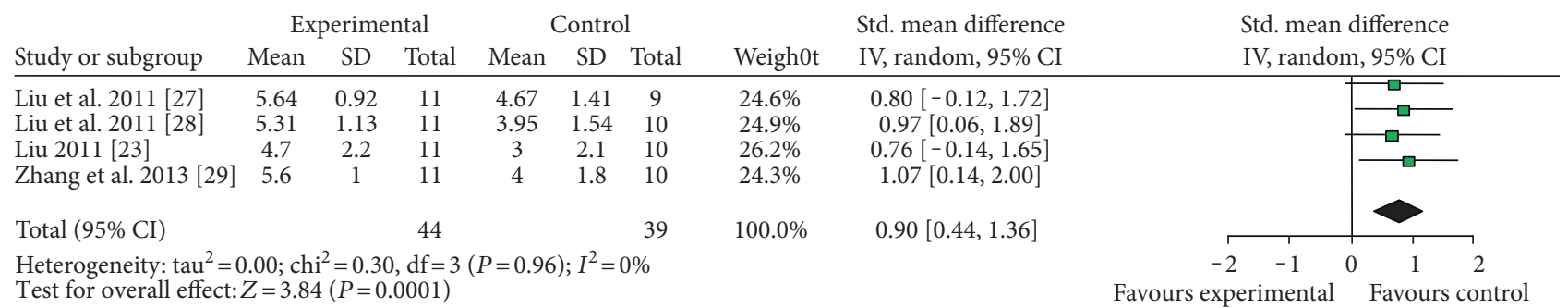

(a)

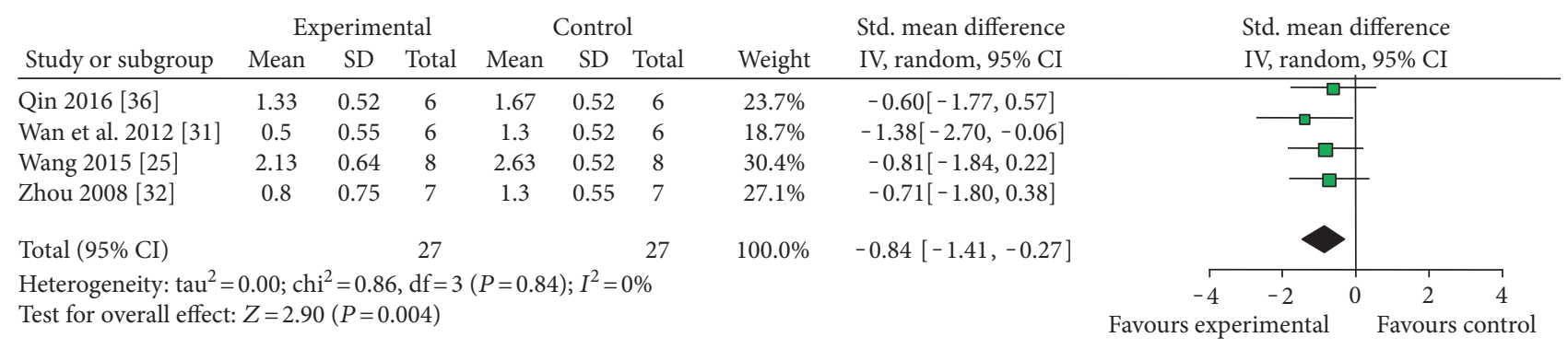

(b)

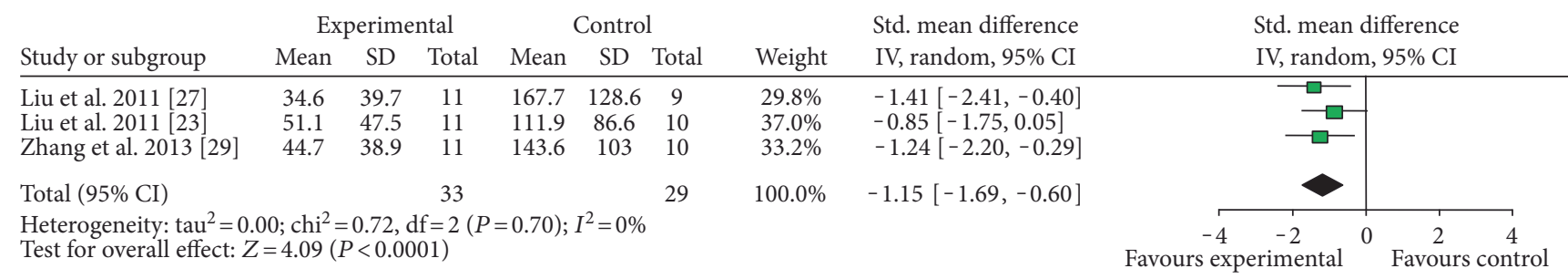

(c)

FIGURE 4: The forest plot: effects of catalpol for improving NFS compared with the control according to (a) balance beam-walking test, (b) Bederson score, and (c) adhesive removal test.

compared with the control $(n=26, \mathrm{SMD}=-1.22,95 \% \mathrm{CI}$ : $-1.56 \sim-0.88, P<0.00001$; heterogeneity $\chi^{2}=1.29$, $\mathrm{df}=1$, $\left.P=0.26, I^{2}=23 \%\right)$. Meta-analysis of the 5 studies of the 14th day subgroup indicated that catalpol significantly improved the NFS compared with the control $(n=95$, SMD $=-0.89$, 95\% CI: $-1.33 \sim-0.45, P<0.0001$; heterogeneity $\left.\chi^{2}=94.06, \mathrm{df}=4, P<0.00001, I^{2}=96 \%\right)$. As the $I^{2}$ of latter 14th day subgroup was greater than $50 \%$, we conducted a further subgroup analysis according to animal sex. Meta-analysis of 4 studies [23, 27-29] in male subgroup showed that catalpol significantly improved NFS compared with the control $(n=83, \mathrm{SMD}=0.90,95 \% \mathrm{CI}$ : $0.44 \sim 1.36, \quad P=0.0001$; heterogeneity $\chi^{2}=0.30, \quad \mathrm{df}=3$, $P=0.96, I^{2}=0 \%$, Figure 4(a)). Those findings indicated that timing for outcomes assessments and animal sex may be the explanation for the high heterogeneity. Three studies did not provide primary data and thus failed for meta-analysis. Among them, 2 studies $[15,17]$ reported that catalpol significantly improved NFS $(P<0.05)$, whereas one study [18] showed no significance. (3) Bederson score (7 studies): meta-analysis of 4 studies [25, 31, 32, 36] showed significant effect of catalpol for improving NFS according to Bederson score compared with control $(n=54, \mathrm{SMD}=-0.84,95 \% \mathrm{CI}$ :
$-1.41 \sim-0.27, \quad P=0.004$; heterogeneity $\chi^{2}=0.84, \quad \mathrm{df}=3$, $P=0.84 ; I^{2}=0 \%$, Figure $\left.4(\mathrm{~b})\right)$. Three studies failed to pool analysis due to the absence of primary data. Among which, 2 studies $[15,18]$ reported that the effect of catalpol on NFS was significant $(P<0.05)$, but one study [17] showed no significance. (4) Adhesive removal test (4 studies): metaanalysis of 3 studies $[23,27,29]$ indicated that catalpol significantly improved NFS compared with the control according to adhesive removal test $(n=62, \mathrm{SMD}=-1.15,95 \% \mathrm{CI}$ : $-1.69 \sim-0.60, \quad P<0.0001$; heterogeneity $\chi^{2}=0.72, \mathrm{df}=2$, $P=0.70 ; I^{2}=0 \%$, Figure 4(c)). One study [33] also reported the significance $(P<0.05)$ but failed for pool analysis due to the absence of primary data. (5) Bar-grasping test: metaanalysis of 3 studies [23, 28, 29] indicated significant effects of catalpol for improving NFS compared with the control $(n=63, \mathrm{SMD}=1.41,95 \% \mathrm{CI}: 0.66 \sim 2.16, P=0.0002$; heterogeneity $\chi^{2}=3.41, \mathrm{df}=2, P=0.18 ; I^{2}=41 \%$, Figure $\left.5(\mathrm{a})\right)$. (6) Neuromuscular function test (2 studies with 3 comparisons): meta-analysis of 3 comparisons [18, 25] showed no significant effect of catalpol for improving NFS according to neuromuscular function test $(n=40, \mathrm{SMD}=-0.57,95 \%$ CI: $-1.48 \sim 0.35, P=0.23$; heterogeneity $\chi^{2}=3.90, \mathrm{df}=2$, $P=0.14 ; I^{2}=49 \%$, Figure 5(b)). (8) Corner test (3 studies): 


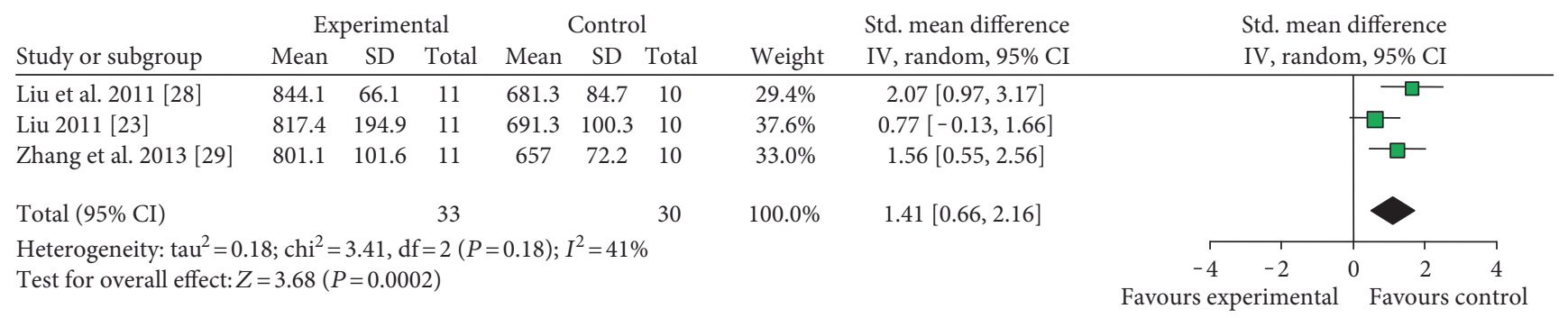

(a)

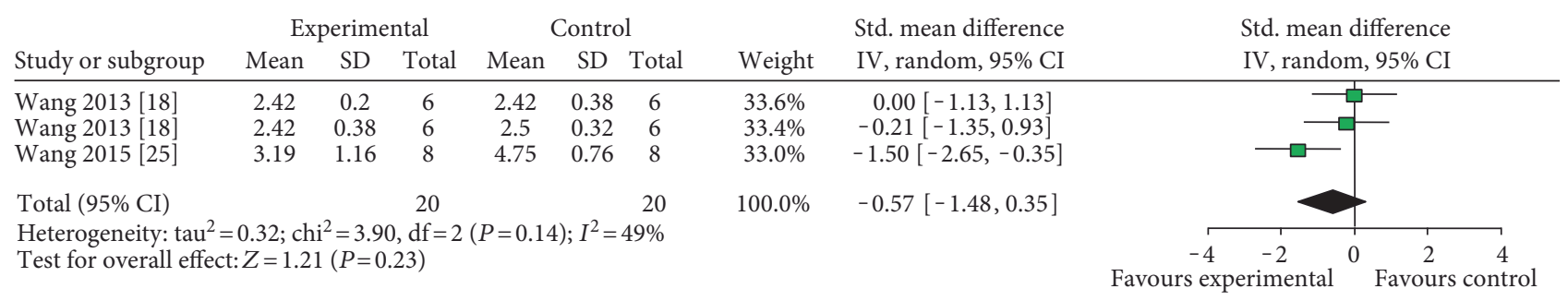

(b)

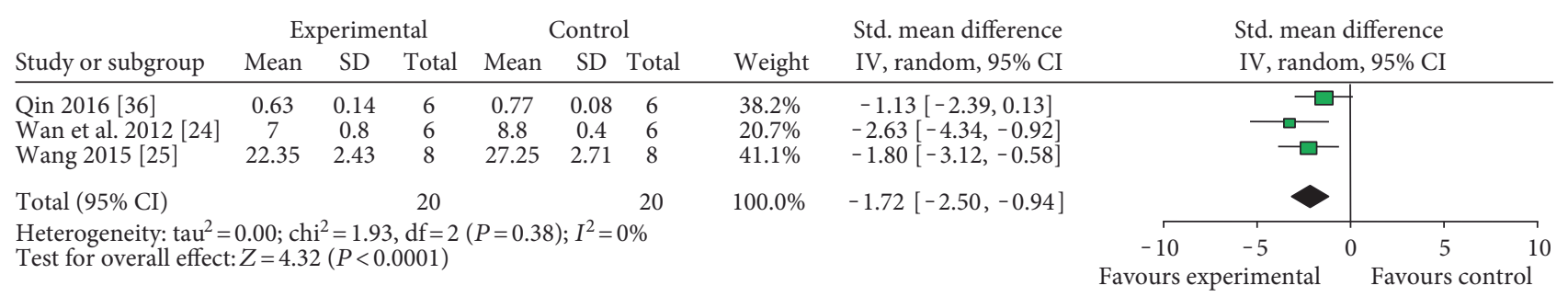

(c)

FIGURE 5: The forest plot: effects of catalpol for improving NFS compared with the control according to (a) bar-grasping test, (b) neuromuscular function test, and (c) corner test.

meta-analysis of 3 studies $[24,25,36]$ showed significant effect of catalpol for improving NFS $(n=40, \mathrm{SMD}=-1.72$, 95\% CI: $-2.50 \sim-0.94, P<0.0001$; heterogeneity $\chi^{2}=1.93$, $\mathrm{df}=2, P=0.38 ; I^{2}=0 \%$, Figure 5(c)). (9) Others: several studies showed significant effects of catalpol for reducing NFS compared with control $(P<0.05$ or $P<0.01)$ according to cylinder test $[26,34,38]$, skilled reaching task test [31], neural comprehensive function test [20], stair test [26], tray task box task test [32], grasping test box test [32], foot-fault test [33, 38], Ladder rung walking test [36], and real-time gait behavior test [30], respectively; one study [15] showed no significance according to skilled reaching task test; three studies showed no significance according to muscular strength test $[15,18,31]$.

3.5. Neuroprotective Mechanisms of Catalpol for Ischemic Stroke. The mechanisms of neuroprotection of catalpol on ischemic stroke were studied in a total of 19 included articles $[14,15,17,18,20-25,27,28,31-36,38]$ and summarized as follows: (1) reduction of oxidative reactions by increasing the activity of SOD, GSH-PX, and catalase, increasing the expression of NOX2 and decreasing the concentration of MDA and NO [20-23]; (2) inhibition of apoptosis by increasing bcl-2 expression and decreasing the expression of cleaved caspase-3, caspase-9, and Bax [22, 23, 36]; (3) repression of inflammatory reactions by decreasing the expression of IL10 [23]; (4) repression of autophagy by increasing LC3 expression [25]; (5) relief of energy exhaustion by decreasing the content of lactic acid, increasing the content of pyruvic acid, and improving the activity of $\mathrm{Na}^{+}$, $\mathrm{K}^{+}$-ATPase and $\mathrm{Ca}^{2+}, \mathrm{Mg}^{2+}$-ATPase $[23,27]$; (6) promotion of survival, reparation, and regeneration of neural cells through increasing the expression of NGF, BDNF, VEGF, bFGF, TrKA, TrkB, AKt, and PI3K, increasing the mRNA levels of NGF, BDNF, TrKA, and AKt, and decreasing CDNF expression and PI3K mRNA [15, 23, 24, 28, 31, 33-35]; (7) enhancement of angiogenesis by increasing the expression of EPO, EPOR, VEGF, JAK2, pJAK2, STAT3, and Ang-1 $[17,18,31-34,38]$; (8) neuroprotection through GLP-1R/ $\beta$-endorphin pathway [14]. Characteristics of mechanism studies of catalpol on experimental ischemic stroke were showed in Table 3.

Currently, more than 140 compounds are being isolated from Radix Rehmanniae, including rehmaglutoside E, ajugol, leucosceptoside A, jionoside D, acteoside, salidrosid, jionoside B1, vanillin, oleanolic acid, and geniposide [40-42]. Liu [42] studied the chemical compounds of Rehmannia glutinosa Libosch and assayed their bioactivities, indicating that rehmaglutoside E, 6-O-E-caffeoyl ajugol, leucosceptoside A, and jionoside $\mathrm{D}$ had antioxidation activities and acteoside, salidrosid, leucosceptoside A, jionoside D, jionoside B1, and vanillin had anti-inflammation activities. Ajugol was reported to repress inflammatory reactions by decreasing the NO in lipopolysaccharide- (LPS-) induced mouse 
TABLE 3: Characteristics of mechanism studies of catalpol on experimental ischemic stroke.

\begin{tabular}{|c|c|c|c|c|}
\hline Study (years) & Model & $\begin{array}{l}\text { Method of administration } \\
\text { (experimental group } \\
\text { versus control group) }\end{array}$ & Observations & Possible mechanisms \\
\hline Jia et al. [14] & $\begin{array}{l}\mathrm{MCAO} / 1 \mathrm{~h} \text { in } \\
\text { Wistar rats }\end{array}$ & Catalpol versus saline & $\begin{array}{l}\text { Increased } \beta \text {-endorphin levels and } \\
\text { the effects were reversed by GLP-1R } \\
\text { orthosteric antagonist }\end{array}$ & $\begin{array}{l}\text { GLP-1R/ } \beta \text {-endorphin } \\
\text { pathway }\end{array}$ \\
\hline & & & Reduced IV and improved NFS & \\
\hline \multirow[t]{2}{*}{$\begin{array}{l}\text { Wan et al. } \\
{[15]}\end{array}$} & $\begin{array}{c}\text { Permanent MCAO in } \\
\text { SD rats }\end{array}$ & $\begin{array}{l}\text { Catalpol versus normal } \\
\text { saline }\end{array}$ & $\begin{array}{c}\text { Increased synapse quantity } \\
\text { upregulated GAP43 expression } \\
\text { Improved NFS }\end{array}$ & $\begin{array}{l}\text { Promotion of survival, } \\
\text { reparation, and regeneration } \\
\text { of neural cells }\end{array}$ \\
\hline & & & $\begin{array}{l}\text { Increased EPO and VEGF } \\
\text { expression }\end{array}$ & \\
\hline $\begin{array}{l}\text { Zhu et al. } \\
\text { [17] }\end{array}$ & $\begin{array}{l}\text { Permanent } \mathrm{MCAO} \text { in } \\
\text { Kunming mice }\end{array}$ & $\begin{array}{c}\text { Catalpol versus normal } \\
\text { saline }\end{array}$ & $\begin{array}{l}\text { Improved NFS, increased VWF and } \\
\text { PCNA co-localization points, } \\
\text { improved the vascular pattern of the } \\
\text { cerebral cortex surface, and reduced } \\
\text { BCEC edema }\end{array}$ & $\begin{array}{l}\text { Enhancement of } \\
\text { angiogenesis }\end{array}$ \\
\hline Wang [18] & $\begin{array}{c}\text { Permanent MCAO in } \\
\text { SD rats }\end{array}$ & $\begin{array}{l}\text { Catalpol versus normal } \\
\text { saline }\end{array}$ & $\begin{array}{c}\text { Upregulated the levels of VEGF, } \\
\text { JAK2, and STAT3 } \\
\text { Reduced IV }\end{array}$ & $\begin{array}{l}\text { Enhancement of } \\
\text { angiogenesis }\end{array}$ \\
\hline $\begin{array}{l}\text { Zhang et al. } \\
{[20]}\end{array}$ & $\begin{array}{l}\text { Permanent MCAO in } \\
\text { Kunming mice }\end{array}$ & $\begin{array}{l}\text { Catalpol versus no } \\
\text { treatment }\end{array}$ & $\begin{array}{l}\text { Increased SOD activity and } \\
\text { decreased MDA and NO } \\
\text { concentration } \\
\text { Improved NFS }\end{array}$ & $\begin{array}{l}\text { Reduction of oxidative } \\
\text { reactions }\end{array}$ \\
\hline $\begin{array}{l}\text { Min et al. } \\
{[21]}\end{array}$ & $\mathrm{MCAO} / 2 \mathrm{~h}$ in $\mathrm{SD}$ rats & $\begin{array}{l}\text { Catalpol versus dimethyl } \\
\text { sulfoxide }\end{array}$ & $\begin{array}{c}\text { Increased GSH-PX activity, } \\
\text { decreasing MDA concentration } \\
\text { Reduced IV and improved NFS }\end{array}$ & $\begin{array}{l}\text { Reduction of oxidative } \\
\text { reactions }\end{array}$ \\
\hline Min [22] & $\mathrm{MCAO} / 2 \mathrm{~h}$ in $\mathrm{SD}$ rats & $\begin{array}{l}\text { Catalpol versus no } \\
\text { treatment }\end{array}$ & $\begin{array}{c}\text { Increased GSH-PX, SOD, and } \\
\text { catalase activity, increased NOX2 } \\
\text { expression, decreased MDA } \\
\text { concentration } \\
\text { Increased bcl-2 expression and } \\
\text { decreased cleaved caspase-3 and Bax } \\
\text { expression } \\
\text { Reduced IV and improved NFS } \\
\text { Reduced apoptotic cells }\end{array}$ & $\begin{array}{l}\text { Reduction of oxidative } \\
\text { reactions } \\
\text { Inhibition of apoptosis }\end{array}$ \\
\hline Liu 2011 [23] & $\mathrm{MCAO} / 2 \mathrm{~h}$ in $\mathrm{SD}$ rats & Catalpol versus edible oil & $\begin{array}{l}\text { Increased SOD activity, decreased } \\
\text { MDA concentration } \\
\text { Decreased IL10 expression } \\
\text { Increased bcl-2 expression and } \\
\text { decreased Bax expression } \\
\text { Increased the expression of NGF, } \\
\text { BDNF, VEGF, bFGF, TrKA, PI3K, } \\
\text { and AKt, increased the mRNA levels } \\
\text { of NGF, BDNF, TrKA, and AKt, } \\
\text { decreased CDNF expression and } \\
\text { PI3K mRNA level } \\
\text { Decreased lactic acid content, } \\
\text { increased pyruvic acid content, and } \\
\text { improved Na } \mathrm{K}^{+} \text {-ATPase and Ca }{ }^{2+} \text {, } \\
\mathrm{Mg}^{2+} \text {-ATPase activities } \\
\text { Improved NFS } \\
\text { Increased neuron number and nissl } \\
\text { body number, improved cerebral } \\
\text { cortex ultrastructure }\end{array}$ & $\begin{array}{c}\text { Reduction of oxidative } \\
\text { reactions } \\
\text { Repression of inflammatory } \\
\text { reactions } \\
\text { Inhibition of apoptosis } \\
\text { Promotion of survival, } \\
\text { reparation, and regeneration } \\
\text { of neural cells } \\
\text { Relief of energy exhaustion }\end{array}$ \\
\hline $\begin{array}{l}\text { Wan et al. } \\
2012[24]\end{array}$ & $\begin{array}{l}\text { Permanent MCAO in } \\
\text { SD rats }\end{array}$ & $\begin{array}{l}\text { Catalpol versus normal } \\
\text { saline }\end{array}$ & $\begin{array}{c}\text { Increased dendritic branches and } \\
\text { spine density and increased P38 } \\
\text { expression } \\
\text { Improved NFS }\end{array}$ & $\begin{array}{l}\text { Promotion of survival, } \\
\text { reparation, and regeneration } \\
\text { of neural cells }\end{array}$ \\
\hline
\end{tabular}


TABLe 3: Continued.

\begin{tabular}{|c|c|c|c|c|}
\hline Study (years) & Model & $\begin{array}{l}\text { Method of administration } \\
\text { (experimental group } \\
\text { versus control group) } \\
\end{array}$ & Observations & Possible mechanisms \\
\hline Wang [25] & $\mathrm{MCAO} / 2 \mathrm{~h}$ in $\mathrm{SD}$ rats & $\begin{array}{c}\text { Catalpol versus normal } \\
\text { saline }\end{array}$ & $\begin{array}{c}\text { Increased LC3 expression } \\
\text { Improved neurovascular unit } \\
\text { structure } \\
\text { Reduced IV and improved NFS }\end{array}$ & Repression of autophagy \\
\hline $\begin{array}{l}\text { Liu et al. } \\
2011 \text { [27] }\end{array}$ & $\begin{array}{c}\text { Permanent MCAO in } \\
\text { SD rats }\end{array}$ & $\begin{array}{c}\text { Catalpol versus distilled } \\
\text { water }\end{array}$ & $\begin{array}{c}\text { Decreased lactic acid content, } \\
\text { increased pyruvic acid content, and } \\
\text { improved } \mathrm{Na}^{+}, \mathrm{K}^{+} \text {-ATPase and } \mathrm{Ca}^{2+}, \\
\mathrm{Mg}^{2+} \text {-ATPase activities } \\
\text { Improved NFS }\end{array}$ & Relief of energy exhaustion \\
\hline $\begin{array}{l}\text { Liu et al. } \\
2011[28]\end{array}$ & $\begin{array}{c}\text { Permanent MCAO in } \\
\text { SD rats }\end{array}$ & Catalpol versus edible oil & $\begin{array}{c}\text { Increased neuron number } \\
\text { Increased the expression and mRNA } \\
\text { levels of NGF and BDNF } \\
\text { Improved NFS }\end{array}$ & $\begin{array}{l}\text { Promotion of survival, } \\
\text { reparation, and regeneration } \\
\text { of neural cells }\end{array}$ \\
\hline $\begin{array}{l}\text { Wan et al. } \\
2012[31]\end{array}$ & $\begin{array}{c}\text { Permanent MCAO in } \\
\text { SD rats }\end{array}$ & $\begin{array}{l}\text { Catalpol versus normal } \\
\text { saline }\end{array}$ & $\begin{array}{l}\text { Increased dendritic branches and } \\
\text { spine density } \\
\text { Increased the expression of EPO, } \\
\text { VEGF, STAT3, GAP-43, P38, } \\
\text { BDNF, and Trk B } \\
\text { Improved NFS }\end{array}$ & $\begin{array}{c}\text { Enhancement of } \\
\text { angiogenesis } \\
\text { Promotion of survival, } \\
\text { reparation, and regeneration } \\
\text { of neural cells }\end{array}$ \\
\hline Zhou [32] & $\begin{array}{c}\text { Permanent MCAO in } \\
\text { SD rats }\end{array}$ & $\begin{array}{l}\text { Catalpol versus normal } \\
\text { saline }\end{array}$ & $\begin{array}{l}\text { Increased Ang-1 expression } \\
\text { Improved NFS }\end{array}$ & $\begin{array}{l}\text { Enhancement of } \\
\text { angiogenesis }\end{array}$ \\
\hline $\begin{array}{l}\text { Wan et al. } \\
2013 \text { [33] }\end{array}$ & $\begin{array}{c}\text { Permanent MCAO in } \\
\text { SD rats }\end{array}$ & $\begin{array}{l}\text { Catalpol versus normal } \\
\text { saline }\end{array}$ & $\begin{array}{l}\text { Increased remodeling and sprouting } \\
\text { of CST axonal } \\
\text { Increased the expression of GAP-43 } \\
\text { Reduced IV and improved NFS }\end{array}$ & $\begin{array}{c}\text { Enhancement of } \\
\text { angiogenesis } \\
\text { Promotion of survival, } \\
\text { reparation, and regeneration } \\
\text { of neural cells }\end{array}$ \\
\hline $\begin{array}{l}\text { Tan et al. } \\
{[34]}\end{array}$ & $\begin{array}{c}\text { Permanent MCAO in } \\
\text { SD rats }\end{array}$ & $\begin{array}{l}\text { Catalpol versus normal } \\
\text { saline }\end{array}$ & $\begin{array}{l}\text { Improved cell morphology and } \\
\text { increased the number of neuron, } \\
\text { glial cells, and vessel length } \\
\text { Improved NFS }\end{array}$ & $\begin{array}{c}\text { Enhancement of } \\
\text { angiogenesis } \\
\text { Promotion of survival, } \\
\text { reparation, and regeneration } \\
\text { of neural cells }\end{array}$ \\
\hline $\begin{array}{l}\text { Zhang et al. } \\
\text { [35] }\end{array}$ & $\begin{array}{c}\text { Permanent MCAO in } \\
\text { SD rats }\end{array}$ & $\begin{array}{l}\text { Catalpol versus edible oil } \\
\text { and normal saline }\end{array}$ & $\begin{array}{l}\text { Improved cell morphology and } \\
\text { increased myelin sheath and } \\
\text { increased MBP expression } \\
\text { Improved NFS }\end{array}$ & $\begin{array}{l}\text { Promotion of survival, } \\
\text { reparation, and regeneration } \\
\text { of neural cells }\end{array}$ \\
\hline Qin [36] & $\begin{array}{c}\text { Permanent MCAO in } \\
\text { SD rats }\end{array}$ & $\begin{array}{l}\text { Catalpol versus normal } \\
\text { saline }\end{array}$ & $\begin{array}{l}\text { Promote the proliferation and } \\
\text { differentiation of neural stem cells } \\
\text { and the survey of neuron } \\
\text { Increased ratio of Bcl- } 2 / \text { Bax, } \\
\text { reduced the expression of caspase- } 9 \\
\text { and caspase- } 3 \\
\text { Improved NFS }\end{array}$ & Inhibition of apoptosis \\
\hline $\begin{array}{l}\text { Wan et al. } \\
{[38]}\end{array}$ & $\begin{array}{c}\text { Permanent MCAO in } \\
\text { SD rats }\end{array}$ & $\begin{array}{l}\text { Catalpol versus no } \\
\text { treatment }\end{array}$ & $\begin{array}{c}\text { Increased VWF-PCNA } \\
\text { colocalization } \\
\text { Increased the expression of EPO, } \\
\text { EPOR, pJAK2, pSTAT3, VEGF, and } \\
\text { VEGF mRNA } \\
\text { Improved NFS }\end{array}$ & $\begin{array}{l}\text { Enhancement of } \\
\text { angiogenesis }\end{array}$ \\
\hline
\end{tabular}

AKt: serine/threonine kinase; Ang-1: angiopoietin 1; BCEC: brain capillary endothelial cells; bcl-2: B-cell lymphoma-2; BDNF: brain-derived neurotrophic factor; bFGF: basic fibroblast growth factor; CDNF: cerebral dopamine neurotrophic factor; CST: corticospinal tract; EPO: erythroprotein; EPOR: erythroprotein receptor; GAP-43: growth-associated protein 43; GLP-1R: glucagon-like peptide-1 receptor; GSH-PX: glutathione peroxidase; HO-1: heme oxygenase-1; IL: interleukin; IV: infarct volume; JAK2: janus kinase 2; MCAO: middle carotid artery occlusion; MDA: malondialdehyde; NFS: neurological function score; NGF: nerve growth factor; PCNA: proliferating cell nuclear antigen; PI3K: phosphoinositide-3 kinase; pJAK2: phosphorylated janus kinase 2; pSTAT3: phosphorylated signal transducer and activator of transcription-3; SD: Sprague Dawley; SOD: superoxide dismutase; STAT3: the Stroke Therapy Academic Industry Roundtable; TrKA: tyrosine kinase receptor A; TrKB: tyrosine kinase receptor B; VEGF: vascular endothelial growth factor; VWF: Von Willebrand factor. 


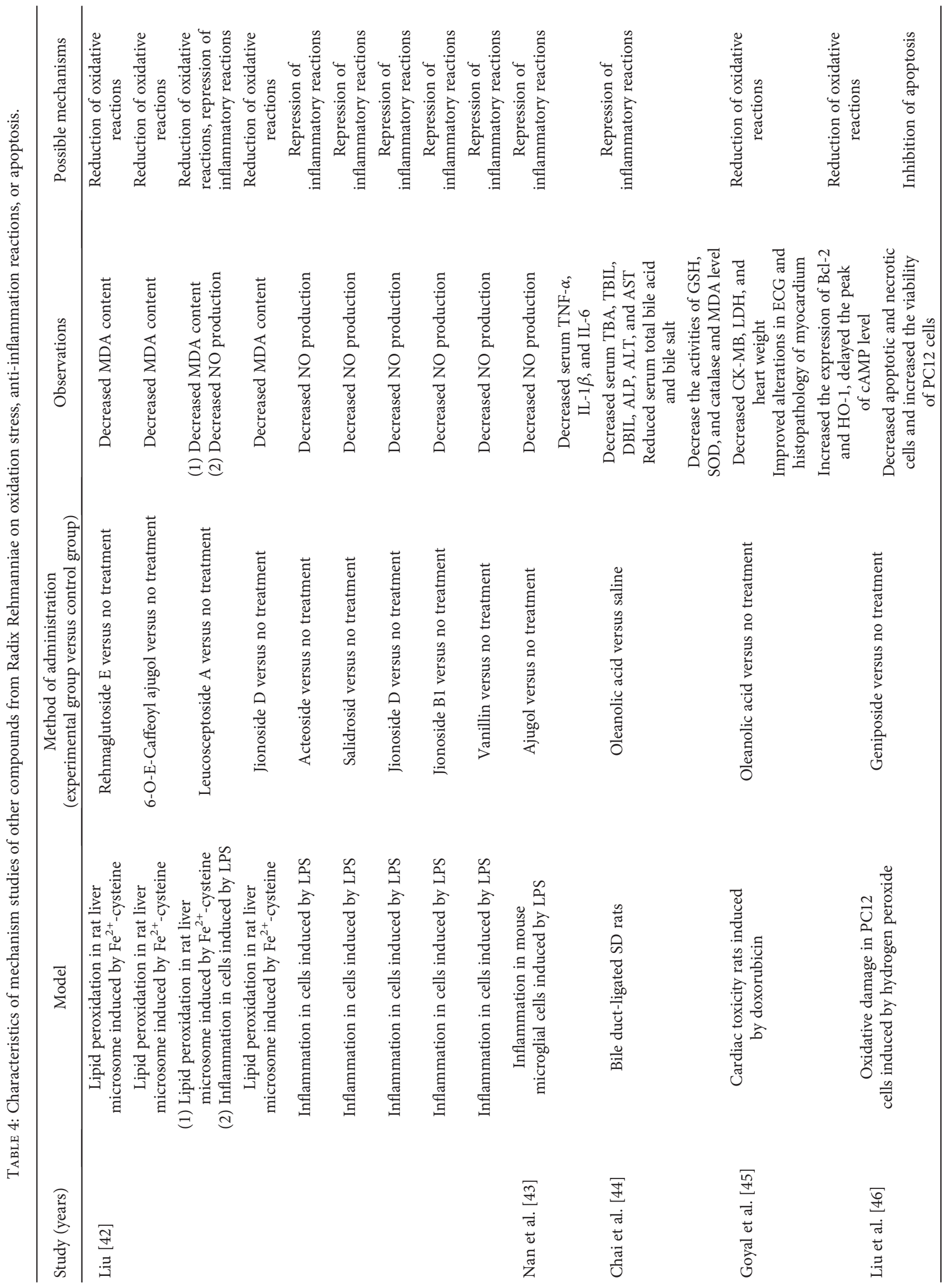




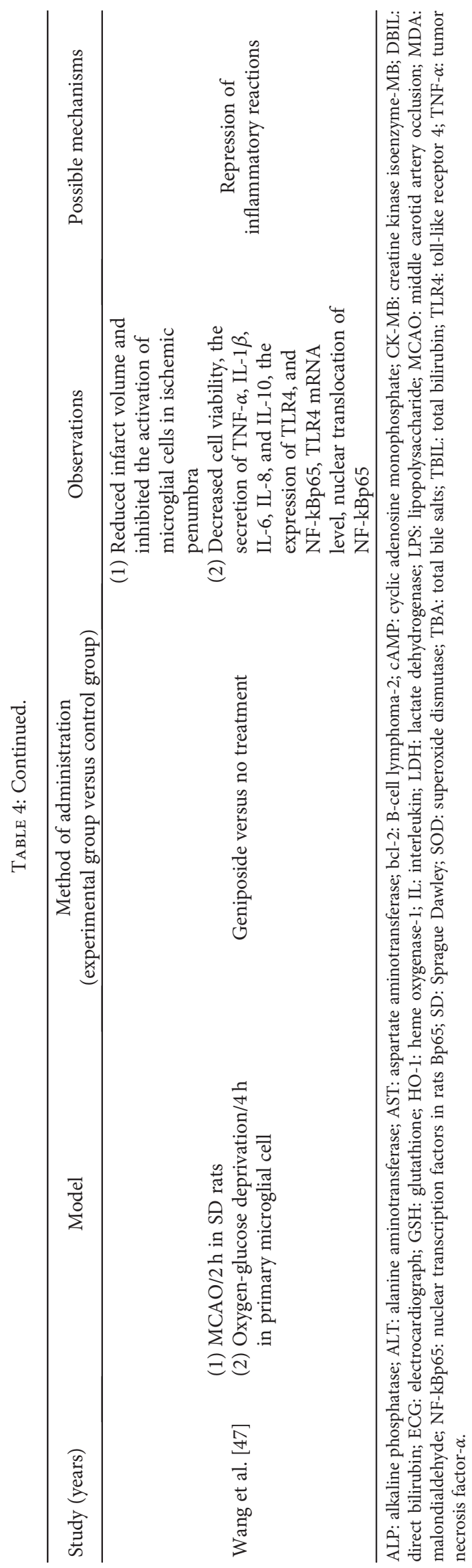


microglial cells [43]. Oleanolic acid attenuated inflammation in bile duct-ligated SD rats through decreasing serum TNF- $\alpha$, IL-1 $\beta$, and IL-6 [44] and attenuated oxidative reactions in cardiac toxicity SD rats by decreasing activities of GSH, SOD, and catalase and attenuating the level of MDA [45]. Liu et al. [46] demonstrated that geniposide exerted antioxidation activities by increasing the expression of $\mathrm{Bcl}-2$ and HO-1 in PC12 cells induced by hydrogen peroxide. Besides, geniposide was reported to decrease the secretion of TNF- $\alpha$, IL- $1 \beta$, IL-6, IL-8, and IL-10 in primary microglial cell oxygen-glucose deprivation $/ 4 \mathrm{~h}$ model, showing antiinflammation activities [47]. Characteristics of those mechanism studies were showed in Table 4.

\section{Discussion}

4.1. Efficacy of Catalpol. To our knowledge, it is the first systematic review that investigated the efficacy of catalpol for experimental acute focal ischemic stroke. Our analysis of 25 studies with 805 animals showed that catalpol significantly reduced IV and improved NFS, suggesting the potential neuroprotective functions of catalpol in experimental acute focal ischemic stroke. However, given the methodological flaws, the overall available evidence from the present study should be interpreted cautiously.

4.2. Limitations. Some limitations should be considered while interpreting our study. First, we only included studies from Chinese and English databases. The absence of studies written in other languages may, to a certain degree, generate selective bias [48]. Second, only 5 out of 25 studies were English papers and the remaining ones were all Chinese papers, thereby limiting generalization of the findings. Third, the quality scores ranging from 2 to 7 points revealed low methodological quality of included studies. Most of the research had flaws in aspects of randomization, allocation concealment, and blinding and sample size calculation, which are the core standards of study design [49]. In addition, none of the included studies used animals with relevant comorbidities, which would have created more relevant models for human pathology [49]. Thus, the present study should be interpreted cautiously.

4.3. Implications. There is a wealth of evidence showing the poor design of animal research [50], which is considered as a roadblock to translate animal research into promising preclinical drug treatments for human disease [51]. In the present study, the low quality of included studies rests with inherent limitations in the primary studies. Thus, some measurements have been developed to directly or indirectly overcome methodology quality issues for animal researches. The animal research: reporting in vivo experiments (ARRIVE) [52] is a reporting guideline consisting of a 20-item checklist for the Introduction, Methods, Results, and Discussion. We recommend to use the ARRIVE guidelines when designing animal research on catalpol, in order to improve the methodological quality. The Stroke Therapy Academic Industry Roundtable (STAIR) meetings [53] provide recommendations on dose, time window, design, outcome assessment, animal species, and model of preclinical studies of acute stroke. We also suggest utilizing the STAIR recommendations specifically for the study of catalpol treatment for experimental stroke.

It is disappointing that many drugs that showed significant effects and looked promising in animal researches failed to translate into clinical drug treatments [54]. The application of excessive drug doses and the timing of drug administration in animal models, which are inapplicable for human disease, are considered to be two of the main reasons for the failure to translate from animal models to human [54]. In the present systematic review, doses of catalpol and timing for initial administration in animal models were inconsistent among the 25 included studies. Thus, we suggest further studies to determinate the optimal gradient doses and timing of administration in animal models of acute ischemic stroke.

The molecular and biological mechanisms of the neuroprotective effects of catalpol have not been fully elucidated. The present study showed that catalpol had neuroprotective effects for ischemic stroke through different mechanisms as follows: (1) reduction of oxidative reactions by increasing the activity of SOD, GSH-PX, and catalase, increasing the expression of NOX2 and decreasing the concentration of MDA and NO; (2) inhibition of apoptosis by increasing bcl-2 expression and decreasing the expression of cleaved caspase-3, caspase-9, and Bax; (3) repression of inflammatory reactions by decreasing the expression of IL10; (4) repression of autophagy by increasing LC3 expression; (5) relief of energy exhaustion by decreasing lactic acid content, increasing pyruvic acid content, and improving the activity of $\mathrm{Na}^{+}, \mathrm{K}^{+}$-ATPase and $\mathrm{Ca}^{2+}, \mathrm{Mg}^{2+}$-ATPase; (6) promotion of survival, reparation, and regeneration of neural cells through upregulating the expression of VEGF, bFGF, TrKA, TrkB, AKt, and PI3K; (7) enhancement of angiogenesis by upregulating the expression of EPO, EPOR, VEGF, JAK2, pJAK2, STAT3, and Ang-1; (8) neuroprotection through GLP-1R/ $\beta$-endorphin pathway. Besides, other compounds from Radix Rehmanniae were reported to have antioxidation, anti-inflammation, and antiapoptosis activities. However, the efficacy of catalpol in terms of cellular and molecular alteration mechanisms along with functional improvement is worthy of further studies.

A total of 18 measuring methods for NFS were used in the 25 included studies, which indicated that the measuring methods for NFS were diverse and inconsistent. Whether and how the different measuring methods for NFS would affect the result of animal studies of acute ischemic stroke is expected to be further studied. Moreover, it is necessary to explore the accuracy of different measuring methods for NFS to filtrate optimum standards for NFS.

\section{Conclusion}

The present study demonstrated that catalpol could improve NFS and reduce IV, exerting potential neuroprotective effects on experimental acute focal ischemic stroke, mainly through reducing oxidative reaction, inhibiting apoptosis, 
and repressing inflammatory reactions and autophagy. In addition, catalpol may be a promising candidate for clinical trials. Future rigor-randomized controlled trials are needed.

\section{Abbreviations}

\begin{tabular}{|c|c|}
\hline AKt: & Serine/threonine kinase \\
\hline Ang-1: & Angiopoietin 1 \\
\hline ARRIVE: & $\begin{array}{l}\text { The animal research: reporting in vivo } \\
\text { experiments }\end{array}$ \\
\hline bcl-2: & B-cell lymphoma-2 \\
\hline BDNF: & Brain-derived neurotrophic factor \\
\hline bFGF: & Basic fibroblast growth factor \\
\hline CAMARADES: & $\begin{array}{l}\text { Collaborative Approach to Meta-Analysis } \\
\text { and Review of Animal Data from Experi- } \\
\text { mental Studies }\end{array}$ \\
\hline CDNF: & Cerebral dopamine neurotrophic factor \\
\hline CNKI: & National Knowledge Infrastructure \\
\hline df: & Degrees of freedom \\
\hline EMBASE: & Excerpta Medica Database \\
\hline EPO: & Erythroprotein \\
\hline EPOR: & Erythroprotein receptor \\
\hline GAP-43: & Growth-associated protein 43 \\
\hline GLP-1R: & Glucagon-like peptide- 1 receptor \\
\hline GSH-PX: & Glutathione peroxidase \\
\hline HO-1: & Heme oxygenase-1 \\
\hline IL: & Interleukin \\
\hline IV: & Infarct volume \\
\hline JAK2: & Janus kinase 2 \\
\hline KDR: & Kinase insert domain-containing receptor \\
\hline ALP: & Alkaline phosphatase \\
\hline MCAO: & Middle carotid artery occlusion \\
\hline MDA: & Malondialdehyde \\
\hline NFS: & Neurological function score \\
\hline NGF: & Nerve growth factor \\
\hline NOX2: & $\begin{array}{l}\text { Nicotinamide adenine dinucleotide } 2^{\prime} \text { - } \\
\text { phosphate oxidase } 2\end{array}$ \\
\hline PCNA: & Proliferating cell nuclear antigen \\
\hline Ph.D.: & Philosophiae Doctor \\
\hline PI3K: & Phosphoinositide-3 kinase \\
\hline pJAK2: & Phosphorylated janus kinase 2 \\
\hline SD: & Sprague Dawley \\
\hline SMD: & Standard mean difference \\
\hline SOD: & Superoxide dismutase \\
\hline STAIR: & $\begin{array}{l}\text { The Stroke Therapy Academic Industry } \\
\text { Roundtable }\end{array}$ \\
\hline STAT3: & $\begin{array}{l}\text { Signal Transducer and Activator of Tran- } \\
\text { scription } 3\end{array}$ \\
\hline TrKA: & Tyrosine kinase receptor A \\
\hline TrKB: & Tyrosine kinase receptor B \\
\hline TTC: & 2,3,5-Triphenyltetrazolium chloride \\
\hline VEGF: & Vascular endothelial growth factor \\
\hline VWF: & Von Willebrand factor \\
\hline ZL: & Zea Longa. \\
\hline
\end{tabular}

\section{Conflicts of Interest}

None of the authors have potential competing interests to be disclosed.

\section{Authors' Contributions}

Xia-wei Zheng, Wen-ting Yang, and Shuang Chen contributed equally to this work.

\section{Acknowledgments}

This project was supported by the grant of the National Natural Science Foundation of China (81573750/81473491/ 81173395/H2902); the Young and Middle-Aged University Discipline Leaders of Zhejiang Province, China (2013277); and the Zhejiang Provincial Program for the Cultivation of High-level Health talents (2015).

\section{References}

[1] E. C. Jauch, J. L. Saver, H. P. Adams et al., "Guidelines for the early management of patients with acute ischemic stroke: a guideline for healthcare professionals from the American Heart Association/American Stroke Association," Stroke, vol. 44, no. 3, pp. 870-947, 2013.

[2] A. Moretti, F. Ferrari, and R. F. Villa, "Neuroprotection for ischaemic stroke: current status and challenges," Pharmacology \& Therapeutics, vol. 146, pp. 23-34, 2015.

[3] A. Tuttolomondo, R. Pecoraro, V. Arnao, R. Maugeri, D. G. Iacopino, and A. Pinto, "Developing drug strategies for the neuroprotective treatment of acute ischemic stroke," Expert Review of Neurotherapeutics, vol. 15, no. 11, pp. 1271-1284, 2015.

[4] A. Majid, "Neuroprotection in stroke: past, present, and future," ISRN Neurology, vol. 2014, Article ID 515716, 17 pages, 2014.

[5] S. Grupke, J. Hall, M. Dobbs, G. J. Bix, and J. F. Fraser, "Understanding history, and not repeating it. Neuroprotection for acute ischemic stroke: from review to preview," Clinical Neurology and Neurosurgery, vol. 129, pp. 1-9, 2015.

[6] W. Zhou, X. Cheng, and Y. Zhang, "Effect of Liuwei Dihuang decoction, a traditional Chinese medicinal prescription, on the neuroendocrine immunomodulation network," Pharmacology \& Therapeutics, vol. 162, pp. 170-178, 2016.

[7] L. Lin, Q. Wang, Y. Yi, S. Wang, and Z. Qiu, "Liuwei Dihuang pills enhance the effect of Western medicine in treating diabetic nephropathy: a meta-analysis of randomized controlled trials," Evidence-Based Complementary and Alternative Medicine, vol. 2016, Article ID 1509063, 9 pages, 2016.

[8] S. Tong, L. Chen, Q. Zhang, J. Liu, J. Yan, and Y. ItoSeparation of catalpol from Rehmannia glutinosa Libosch. By high-speed countercurrent chromatography," Journal of Chromatographic Science, vol. 53, no. 5, pp. 725-729, 2015.

[9] B. Jiang, R. F. Shen, J. Bi, X. S. Tian, T. Hinchliffe, and Y. Xia, "Catalpol: a potential therapeutic for neurodegenerative diseases," Current Medicinal Chemistry, vol. 22, no. 10, pp. 1278-1291, 2015.

[10] W. Dong, Y. Xian, W. Yuan et al., "Catalpol stimulates VEGF production via the JAK2/STAT3 pathway to improve angiogenesis in Rats' stroke model," Journal of Ethnopharmacology, vol. 191, pp. 169-179, 2016.

[11] P. Glasziou, J. P. Vandenbroucke, and I. Chalmers, “Assessing the quality of research," BMJ, vol. 328, no. 7430, pp. 39-41, 2004. 
[12] S. P. Murphy and A. N. Murphy, "Pre-clinical systematic review," Journal of Neurochemistry, vol. 115, no. 4, p. 805, 2010.

[13] M. R. Macleod, T. O'Collins, D. W. Howells, and G. A. Donnan, "Pooling of animal experimental data reveals influence of study design and publication bias," Stroke, vol. 35, no. 5, pp. 1203-1208, 2004.

[14] Y. Jia, N. Gong, T. F. Li, B. Zhu, and Y. X. Wang, "Peptidic exenatide and herbal catalpol mediate neuroprotection via the hippocampal GLP-1 receptor/ $\beta$-endorphin pathway," Pharmacological Research, vol. 102, pp. 276-285, 2015.

[15] D. Wan, H. F. Zhu, Y. Luo, and P. Xie, "Changes in synapse quantity and growth associated protein 43 expression in the motor cortex of focal cerebral ischemic rats following catalpol treatment," Neural Regeneration Research, vol. 6, no. 18, pp. 1380-1385, 2011.

[16] D. Wan, L. Xue, H. Zhu, and Y. Luo, "Catalpol induces neuroprotection and prevents memory dysfunction through the cholinergic system and BDNF," Evidence-Based Complementary and Alternative Medicine, vol. 2013, Article ID 134852, 9 pages, 2013.

[17] H. F. Zhu, D. Wan, Y. Luo, J. L. Zhou, L. Chen, and X. Y. Xu, "Catalpol increases brain angiogenesis and up-regulates VEGF and EPO in the rat after permanent middle cerebral artery occlusion," International Journal of Biological Sciences, vol. 6, no. 5, pp. 443-453, 2010.

[18] H. L. Wang, Comparison in Two Methods of Making pMCAO and the Effect of Catalpol, [M.S. Thesis], Southwest University, Chinese National Knowledge Infrastructure, Beijing, China, 2013, http://kns.cnki.net/KCMS/detail/detail.aspx?dbcode= CMFD\&dbname $=$ CMFD201302\&filename $=1013265468 . n h \&$ v=MzE3MTdXTTFGckNVUkwyZlplUnBGeTNsVmJ6S1ZG MjZIYkcrRzlYS3A1RWJQSVI4ZVgxTHV4WVM3RGgxVD $\mathrm{NxVHI}=$.

[19] L. J. Xue, Catalpol Protects Cerebral Infarction and Improves Memory, [M.S. Thesis], Southwest University, Chinese National Knowledge Infrastructure, Beijing, China, 2012, http://kns.cnki. net/KCMS/detail/detail.aspx?dbcode $=$ CMFD\&dbname $=C M F$ D2012\&filename $=1012344191 . n h \& v=M j U x N T d J U j h l W D F M$ dXhZUzdEaDFUM3FUcldNMUZyQ1VSTDJmWmVScEZ5 M2xXcnJJVkYyNkhMQzhHdERGcnBFYlA=.

[20] C. C. Zhang, J. L. Liu, Y. Li, H. Min, and X. Y. Xu, "The protective effect of puerarin, catalpol and their compatibility on ischemic injury in mice," in The fifth national clinical Chinese material medica academic symposium proceedings, China Association of Chinese Medicine, Wuhan, China, 1st Oct., 2012, http://kns.cnki.net/KCMS/detail/detail.aspx?dbcode $=$ C PFD\&dbname $=$ CPFD0914\&filename $=$ ZHZY201210002039\& $\mathrm{v}=$ MzAyOTZ1aGRobmo5OFRuanFxeGRFZU1PVUtyaWZad UZ2RkN2aVU3ak1KRm9jUHlYUmQ3RzRIOVBOcjQ5Rlp1 c01CUk5L.

[21] Y. Y. Min, C. H. Feng, Z. J. Gao, L. N. Zhang, and Q. Wang, "Protective effect of catalpol on cerebral ischemia reperfusion injury in rats," Progress in Modern Biomedicine, vol. 12, no. 20, pp. 3805-3808, 2012.

[22] Y. Y. Min, Protective Effect of Catalpol on Cerebral Ischemial Reperfusion Injury in Rats and the Underlying Mechanism. [M.S. Thesis], The Fourth Military Medical University, Chinese National Knowledge Infrastructure, Beijing, China, 2015, http://kns.cnki.net/KCMS/detail/detail.aspx?dbcode= CMFD\&dbname $=$ CMFD201601\&filename $=1015961423 . \mathrm{nh} \&$ v=MTUxMDBGckNVUkwyZlplUnBGeTNtVTczUFZGMjZ
HN3ErSDIYT3JKRWJQSVI4ZVgxTHV4WVM3RGgxVDNx VHJXTTE $=$.

[23] M. Liu, Effect of Catalpol on Early Recovery of Neurological Function Recovery after Cerebral Ischemia in Rats and Its Mechanisms, [Ph.D. Thesis], Beijing University of Chinese Medicine, Chinese National Knowledge Infrastructure, Beijing, China, 2011, http://kns.cnki.net/KCMS/detail/detail. asp $x$ ?dbcode $=$ CDFD \&dbname $=$ CDFD0911 \&filename $=10111$ 17963.nh\&v=MjM1MjFGMjZIN0s1R2RqS3JKRWJQSVI4ZV gxTHV4WVM3RGgxVDNxVHJXTTFGckNVUkwyZlplUnB GeTNtVUxySVY=.

[24] D. Wan, H. F. Zhu, Y. Luo, and P. Xie, "Effects of catalpol on dendritic outgrowth and synaptophysin expression in the peri-infarct cortex of rats with permenant middle cerebral artery occlusion," Chinese Pharmacological Bulletin, vol. 28, no. 11, pp. 575-521, 2012.

[25] T. Wang, The Protective Effect of Catalpol on Neurovascular Unit, [M.S. Thesis], Southwest University, Chinese National Knowledge Infrastructure, Beijing, China, 2015, http://kns. cnki.net/KCMS/detail/detail.aspx?dbcode $=$ CMFD\&dbname $=$ CMFD201502\&filename $=1015336477 . n h \& v=M j A y N z l O V k Y$ yNkc3QzdHTlhMcUpFYlBJUjhlWDFMdXhZUzdEaDFUM3 FUcldNMUZyQ1VSTDJmWmVScEZ5M21Wcno=.

[26] Y. Wang, H. F. Zhu, X. Y. Xu, S. M. Wang, G. Chen, and A. Li, "Effect of combined use of catalpol and electroacupuncture on neurological behavioral assessment after cerebral ischemia-reperfusion injury in rats," in The second national clinical Chinese material medica academic symposium proceedings, China Association of Chinese Medicine, Nanning, China, 1st July, 2009, http://d.wanfangdata.com .cn/Conference/7189132.

[27] M. Liu, J. N. Sun, S. F. Dong, Y. Li, H. P. Hu, and J. S. Tang, "Influence of catalpol on early recovery of sensorimotor function and energy metabolism in rats with permanent cerebral ischemia injury," Journal of Beijing University of Traditional Chinese Medicine, vol. 34, no. 4, pp. 245-249, 2011.

[28] M. Liu, Y. Liu, Y. Zhang, J. N. Sun, J. S. Tang, and Z. Y. Xuan, "Catalpol up-regulated NGF, BDNF and mRNA gene expression and improved behavior outcome of rats with ischemic stroke," China Journal of Traditional Chinese Medicine and Pharmacy, vol. 05, pp. 977-981, 2011.

[29] S. W. Zhang, S. F. Dong, J. Q. Li, T. Wu, J. N. Sun, and Z. Y. Xuan, "Neuronal protective effect and mechanism of catalpol on acute and subacute phase after cerebral ischemia," Word Science and Technology/Modernization of Traditional Chinese Medicine and Materia Medica, vol. 15, no. 8, pp. 1682-1687, 2013.

[30] S. W. Zhang, S. F. Dong, T. Wu, and J. N. Sun, "Influence of catalpol on real-time gait analysis of cerebral ischemia in rats," Word Science and Technology/Modernization of Traditional Chinese Medicine and Materia Medica, vol. 15, no. 8, pp. 1676-1681, 2013.

[31] D. Wan, H. F. Zhu, Y. Luo, P. Xie, and J. L. Zhou, "Observation and evaluation of a neurologic function recovery treatment with catalpol in rat after permanent middle cerebral artery occlusion," Chinese Pharmacological Bulletin, vol. 28, no. 9, pp. 1208-1214, 2012.

[32] J. L. Zhou, The Construction of Behavior Testing Method in the Focal Cerebral Ischemia of Rats and Effects of Catalpol on Neurovascular Restoration, [M.S. Thesis], Chongqing Medical University, Chinese National Knowledge Infrastructure, Beijing, China, 2008, http://kns.cnki.net/KCMS/detail/detail 
asp $x$ dbcode $=$ CMFD $\&$ dbname $=$ CMFD2009\&filename $=2008$ 177078.nh\&v=MzA3NDFYMUx1eFlTN0RoMVQzcVRyV00 xRnJDVVJMMmZaZVJwRnkzbVY3ck9WMTI3RnJLL0dkSE xwNUViUElSOGU=.

[33] D. Wan, H. F. Zhu, F. J. Lu, Y. Luo, and P. Xie, "Catalpol promotes corticospinal tract sprouting and remodeling after focal cerebral ischemic stroke in rats," Chinese Pharmacological Bulletin, vol. 29, no. 8, pp. 1057-1063, 2013.

[34] L. L. Tan, D. D. Cui, H. F. Zhu, D. Wan, and J. Ren, "Effect of catalpol on structure of neurovascular unit after focal cerebral ischemia," Chinese Pharmacological Bulletin, vol. 30, no. 1, pp. 44-48, 2014.

[35] X. S. Zhang, L. T. Zhao, G. Y. Zhong, R. Hu, and J. N. Sun, "The study of catalpol on nerve function and myelin sheath protection research in cerebral ischemia injury rats," Journal of Pharmacology and Clinics of Chinese Materia Medica, vol. 02, pp. 46-49, 2016.

[36] L. Qin, The Effect of Catalpol on Proliferation and Differentiation of Neural Stem Cell and Study of Neuroprotection Induced by Catalpol after Permanent Middle Cerebral Artery Occlusion in Rats, [M.S. Thesis], Southwest University, Chinese National Knowledge Infrastructure, Beijing, China, 2016, http://kns .cnki.net/KCMS/detail/detail.aspx?dbcode $=$ CMFD\&dbname $=\mathrm{C}$ MFD201701\&filename $=1016767559$. nh\&uid $=$ WEEvREcwSIJ HSldRa1FhdXNXYXJwZDB6b0pMS0xWV1RpSFRTTmtzW mpxST0=\$9A4hF_YAuvQ5obgVAqNKPCYcEjKensW4ggI8F m4gTkoUKaID8j8gFw!!\&v=MzE0NDIyNkdMUytHZFRKcH BFYlBJUjhlWDFMdXhZUzdEaDFUM3FUcldNMUZyQ1VS TDJmWXVadUZ5amdVYnJCVkY=.

[37] F. Zhang, The Experimental Investigation of the ZG Compatibility Effect to Cerebral Edema of rat, [M.S. Thesis], Southwest University, Chinese National Knowledge Infrastructure, Beijing, China, 2011, http://kns.cnki.net/KCMS/detail/detail. aspx? dbcode $=$ CMFD\&dbname $=$ CMFD2011\&filename $=101$ 1113626.nh\&uid=WEEvREcwSlJHSldRa1FhdXNXYXJwZDB 6b0pMS0xWV1RpSFRTTmtzWmpxST0=\$9A4hF_YAuvQ5 obgVAqNKPCYcEjKensW4ggI8Fm4gTkoUKaID8j8gFw!!\&v= MTk0MTkxRnJDVVJMMmZZdVp1RnlqZ1dyckpWRjI2SDd LNUhkZk9xWkViUElSOGVYMUxleFlTN0RoMVQzcVRy $\mathrm{V} 00=$.

[38] D. Wan, X. Yang, Y. N. Wang et al., "Catalpol stimulates VEGF production via the JAK2/STAT3 pathway to improve angiogenesis in rats' stroke model," Journal of Ethnopharmacology, vol. 191, pp. 169-179, 2016.

[39] C. Schmucker, A. Bluemle, M. Briel et al., "A protocol for a systematic review on the impact of unpublished studies and studies published in the gray literature in meta-analyses," Systematic Reviews, vol. 2, p. 24, 2013.

[40] G. Fu and X. Du, "Research advance on chemical constituents and pharmacological activities of Rehmannia glutinosa," China Medicine and Pharmacy, vol. 15, pp. 39-41, 2015.

[41] H. Li and X. Meng, "Research progress on chemical constituents and pharmacological activities of Rehmannia glutinosa," Drug Evaluation Research, vol. 02, pp. 218-228, 2015.

[42] Y. Liu, Studies on the Active Substances and Function of Rehmannia Radix, Chinese Academy of Medical Science and Peking Union Medical Colloge, [Ph.D. Thesis], Chinese National Knowledge Infrastructure, Beijing, China, 2013, http://kns.cnki.net/KCMS/detail/detail.aspx?dbcode=CDFD\&d bname $=$ CDFD1214\&filename $=1013311933$. nh\&uid $=$ WEEvRE cwSIJHSldRa1Fhb09jMjQxNjlQSUZsVExmYXJZSmtyK2U0e $\mathrm{E} 1 \mathrm{Hdz0}=\$ 9 \mathrm{~A} 4 \mathrm{hF} \_Y$ AuvQ5obgVAqNKPCYcEjKensW4ggI8
Fm4gTkoUKaID8j8gFw!!\&v=MTg4NzdXTTFGckNVUkwy Zll1WnVGeXpoVnJySIZGMjZIYkM1SDlqUHJKRWJQSVI 4ZVgxTHV4WVM3RGgxVDNxVHI=.

[43] Z. D. Nan, M. B. Zhao, K. W. Zeng et al., "Anti-inflammatory iridoids from the stems of Cistanche deserticola cultured in Tarim Desert," Chinese Journal of Natural Medicines, vol. 14, no. 1, pp. 61-65, 2016.

[44] J. Chai, X. Du, S. Chen et al., "Oral administration of oleanolic acid, isolated from Swertia mussotii Franch, attenuates liver injury, inflammation, and cholestasis in bile duct-ligated rats," International Journal of Clinical and Experimental Medicine, vol. 8, no. 2, pp. 1691-1702, 2015.

[45] S. N. Goyal, U. B. Mahajan, G. Chandrayan et al., "Protective effect of oleanolic acid on oxidative injury and cellular abnormalities in doxorubicin induced cardiac toxicity in rats," American Journal of Translational Research, vol. 8, no. 1, pp. 60-69, 2016.

[46] J. Liu, F. Yin, X. Zheng, J. Jing, and Y. Hu, "Geniposide, a novel agonist for GLP-1receptor, prevents PC12 cells from oxidative damage via MAP kinase pathway," Neurochemistry International, vol. 51, no. 6-7, pp. 361-369, 2007.

[47] J. Wang, J. Hou, P. Zhang, D. Li, C. Zhang, and J. Liu, "Geniposide reduces inflammatory responses of oxygen-glucose deprived rat microglial cells via inhibition of the TLR4 signaling pathway," Neurochemical Research, vol. 37, no. 10, pp. 2235$2248,2012$.

[48] G. H. Guyatt, A. D. Oxman, V. Montori et al., "GRADE guidelines: 5. Rating the quality of evidence-publication bias," Journal of Clinical Epidemiology, vol. 64, no. 12, pp. 1277-1282, 2011

[49] S. C. Landis, S. G. Amara, K. Asadullah et al., "A call for transparent reporting to optimize the predictive value of preclinical research," Nature, vol. 490, no. 7419, pp. 187-191, 2012.

[50] D. Moher, M. Avey, G. Antes, and D. G. Altman, "The national institutes of health and guidance for reporting preclinical research," BMC Medicine, vol. 13, p. 34, 2015.

[51] J. Baginskait, "Scientific quality issues in the design and reporting of bioscience research: a systematic study of randomly selected original in vitro, in vivo and clinical study articles listed in the PubMed database," in CAMARADES Monograph, Edinburgh, UK, 2012, http://www.dcn.ed.ac.uk/camarades/ files/Camarades\%20Monograph\%20201201.pdf.

[52] C. Kilkenny, W. J. Browne, I. C. Cuthill, M. Emerson, and D. G. Altman, "Improving bioscience research reporting: the ARRIVE guidelines for reporting animal research," PLoS Biology, vol. 8, no. 6, article e1000412, 2010.

[53] M. Fisher, G. Feuerstein, D. W. Howells et al., "Update of the Stroke Therapy Academic Industry Roundtable preclinical recommendations," Stroke, vol. 40, no. 6, pp. 2244-2250, 2009.

[54] D. Baker, K. Lidster, A. Sottomayor, and S. Amor, "Two years later: journals are not yet enforcing the ARRIVE guidelines on reporting standards for pre-clinical animal studies," PLoS Biology, vol. 12, no. 1, article e1001756, 2014. 


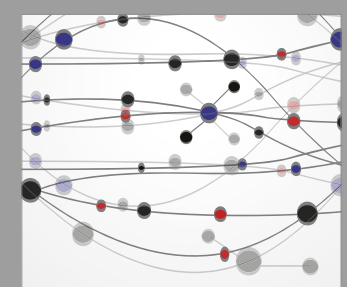

The Scientific World Journal
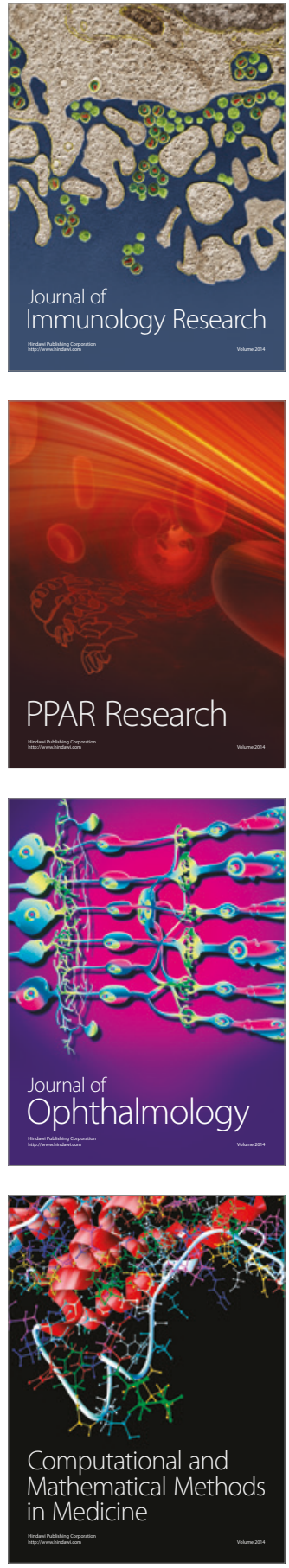

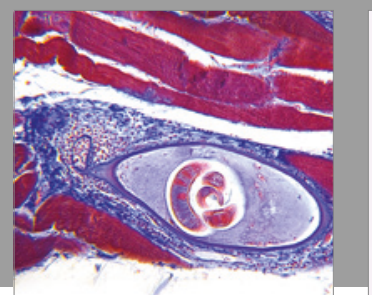

Gastroenterology Research and Practice
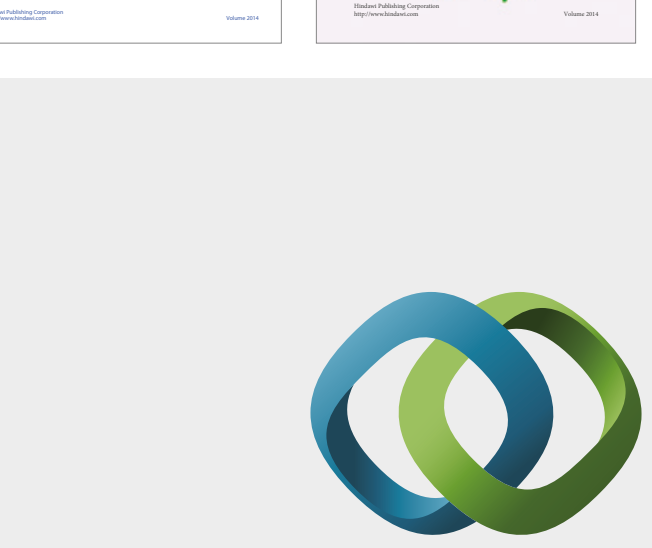

\section{Hindawi}

Submit your manuscripts at

https://www.hindawi.com
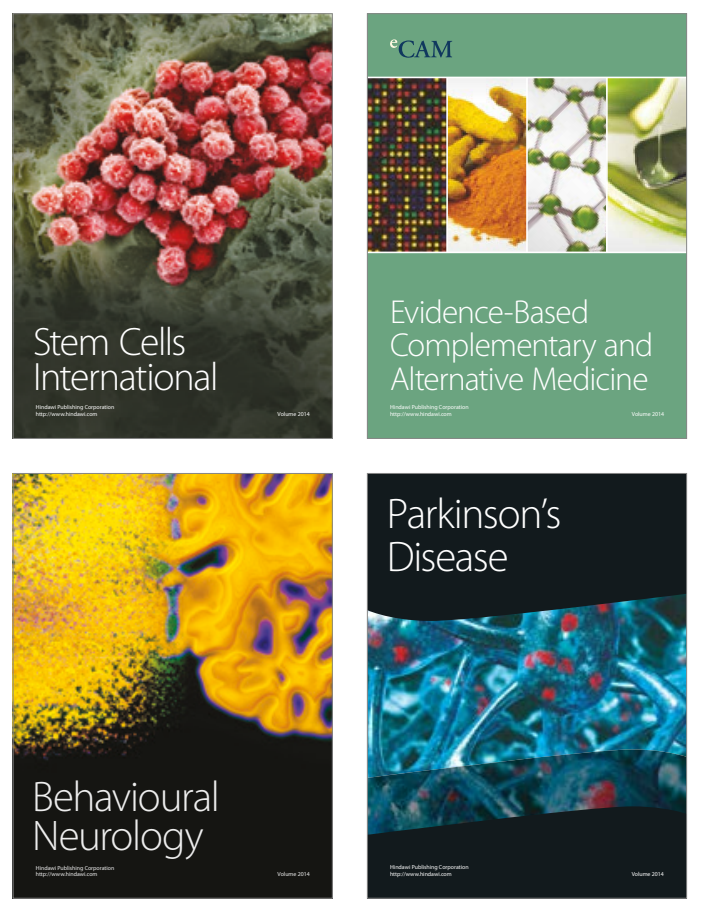
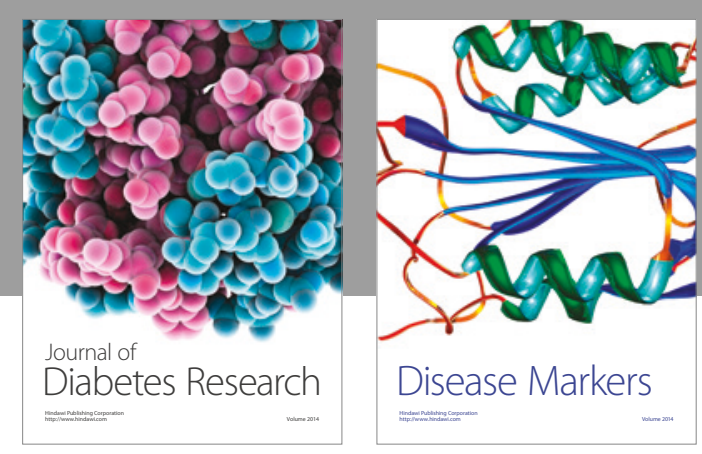

Disease Markers
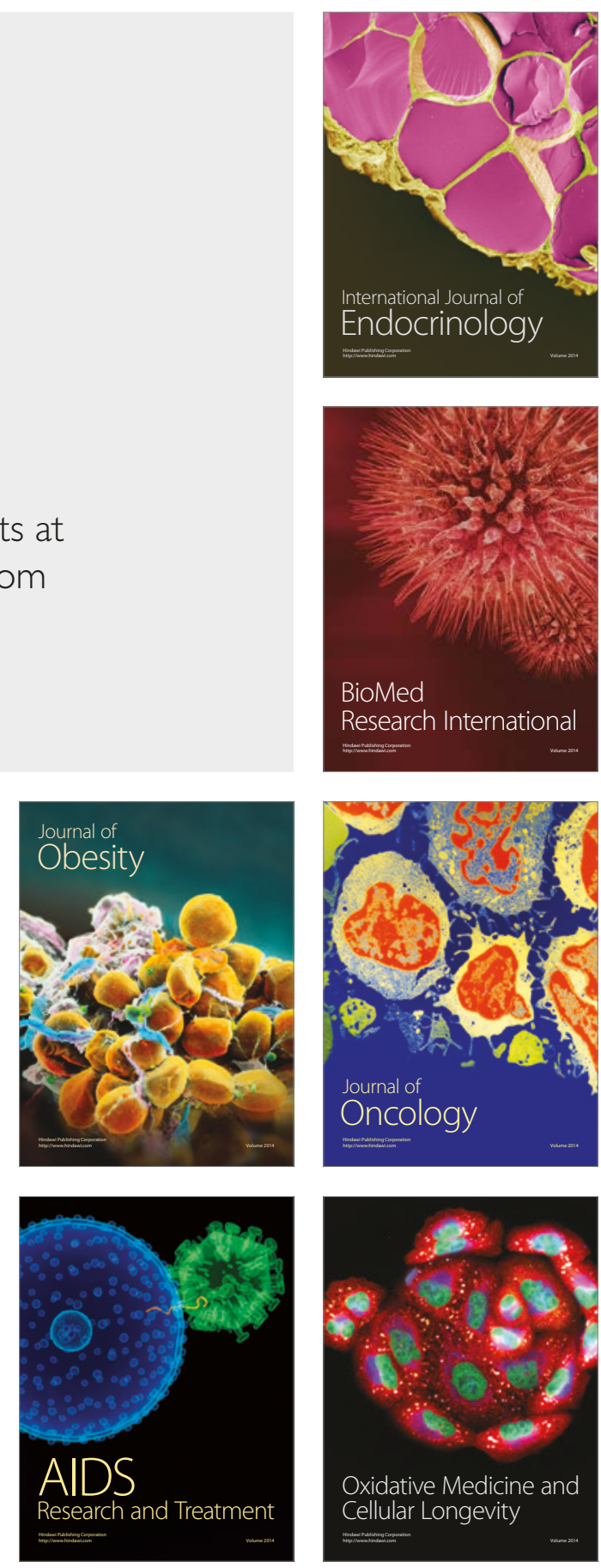